\title{
Antioxidant Materials Based on 2D Nanostructures: A Review on Recent Progresses
}

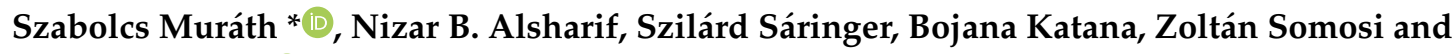 \\ Istvan Szilagyi *(1)
}

MTA-SZTE Lendület Biocolloids Research Group, Interdisciplinary Excellence Centre, Department of Physical Chemistry and Materials Science, University of Szeged, 1 Rerrich Béla tér, H-6720 Szeged, Hungary; nizar.alsharif@chem.u-szeged.hu (N.B.A.); saringer.szilard@chem.u-szeged.hu (S.S.); bkatana@chem.u-szeged.hu (B.K.); somosiz@chem.u-szeged.hu (Z.S.)

* Correspondence: murathsz@chem.u-szeged.hu (S.M.); szistvan@chem.u-szeged.hu (I.S.); Tel.: +36-62-343255 (I.S.)

Received: 31 January 2020; Accepted: 21 February 2020; Published: 26 February 2020

\begin{abstract}
Counteracting reactive oxygen species (ROS, e.g., superoxide radical ion, $\mathrm{H}_{2} \mathrm{O}_{2}$ and hydroxyl radical) is an important task in fighting against oxidative stress-related illnesses and in improving product quality in industrial manufacturing processes. This review focuses on the recent advances on two-dimensional (2D) nanomaterials of antioxidant activity, which are designed for effective decomposition of ROS and thus, for reduction of oxidative stress. Some materials featured in this paper are of uni- or multi-lamellar structures modified with small molecular or enzymatic antioxidants. Others are enzyme-mimicking synthetic compounds (the so-called nanozymes) prepared without antioxidant additives. However, carbon-based materials will not be included, as they were extensively reviewed in the recent past from similar aspects. Given the landmark development around the 2D materials used in various bio-applications, sheet-like antioxidant compounds are of great interest in the scientific and technological communities. Therefore, the authors hope that this review on the recent progresses will be helpful especially for researchers working on novel developments to substantially reduce oxidative stress either in biological systems or industrial liquors.
\end{abstract}

Keywords: antioxidant activity; 2D nanomaterial; nanozyme; clay; enzyme; chalcogenide; metal organic framework; oxidative stress; reactive oxygen species; radical scavenge

\section{Introduction}

Nanomaterials with two-dimensional (2D) structure have attracted notable scientific interest due to their high surface area and intriguing properties arising from their large variety of composition [1-5]. Starting with their light element-based representatives (e.g., graphene, graphite, graphite oxides, carbon nitride, boron nitride and covalent organic frameworks), through metal chalcogenide sheets, layered double hydroxides (LDHs), montmorillonites (MMTs), metal organic frameworks (MOFs) to thin noble metal platelets, one of the main advantages is that their composition is tunable for specific applications. In addition, 2D materials possess unusual electronic, mechanical and optical properties and hence, they can be used as building blocks in a wide range of composites. Concerning the contemporary applications of 2D compounds, they serve as efficient catalysts for water splitting [6-15] or organic reactions [16-21], drug carriers [22-31], sensors [32-39], materials for energy production and storage $[2,15,21,40-49]$ or adsorbers [50-55].

Biocompatible 2D materials gained considerable popularity in the biochemical community, as indicated by the rapidly growing number of their bio-medical applications [56-58]. Among them, 2D antioxidant composites were developed [59-61] and used in decomposition of reactive oxygen species 
(ROS) [62] and subsequently, to reduce oxidative stress in living and industrial systems. Tremendous improvement has been accomplished in the number and variety of antioxidant materials obtained over this period and the following approaches were reported (Figure 1): (i) immobilized natural and artificial enzymes, (ii) 2D materials loaded with molecular antioxidants and (iii) 2D composites of radical scavenging activities (nanozymes). In the present contribution, the antioxidant characteristics of such 2D materials are summarized emphasizing metal-based nano-objects. The carbonaceous materials of 2D structure were greatly investigated in the recent past and collective reviews were published on their applications [57,63-79]. Therefore, carbon-based 2D materials will not be discussed here.

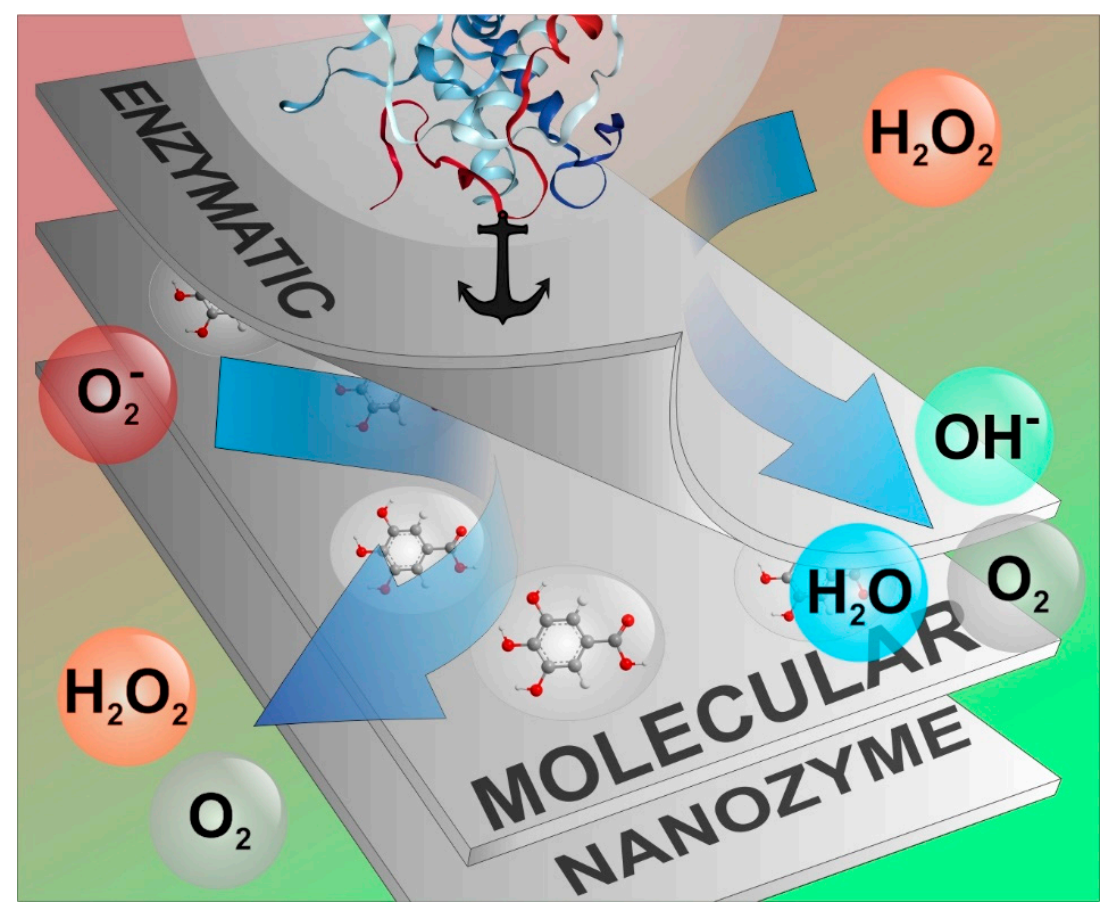

Figure 1. Illustration of molecular and enzymatic antioxidants immobilized in/on layered 2D materials. Schematic representation of superoxide radical anions and $\mathrm{H}_{2} \mathrm{O}_{2}$ is also presented.

\section{Natural Defense Systems versus Oxidative Stress}

The most effective defense systems against reactive oxygen species (ROS), which induce oxidative stress at higher concentrations, are the antioxidant enzymes [80]. ROS include, for instance, superoxide radical anion, $\mathrm{H}_{2} \mathrm{O}_{2}$, hydroxyl and alkoxy radicals of short life time, but of extremely high reactivity [62]. They damage cell constituents leading to the development of various diseases such as chronic inflammation, neurological disorders and cancer [81]. On the other hand, efficient defense against ROS is also required in industrial manufacturing processes (e.g., food, cosmetic and textile industry) to improve the quality of the products $[82,83]$.

Superoxide anion is one of the most notable ROS, since its decomposition by the superoxide dismutase (SOD) enzyme leads to the formation of molecular oxygen and $\mathrm{H}_{2} \mathrm{O}_{2}$. Therefore, the dismutation reaction is also a ROS source. Enzymatic assays were developed to estimate the SOD activity. In the most popular tests, radicals are produced in enzymatic ways and indicator molecules change their color upon reduction by the superoxide anions [84]. Inhibition of the radical-indicator reaction by the enzyme is the measure to assess the dismutation ability.

The two common enzyme groups that can break up $\mathrm{H}_{2} \mathrm{O}_{2}$ are catalases and peroxidases $[85,86]$. During neutralization of harmful peroxides, catalases generate $\mathrm{O}_{2}$ gas and $\mathrm{H}_{2} \mathrm{O}$, while peroxidases perform homolytic bond cleavage on $\mathrm{H}_{2} \mathrm{O}_{2}$ (Figure 1). The as-obtained hydroxyl radicals (OH.) either are consumed by an appropriate substrate near the active site or converted to water. The antioxidant 
enzymes decompose $\mathrm{ROS}$ in tandem reactions in the intracellular environment, e.g., $\mathrm{H}_{2} \mathrm{O}_{2}$ produced by SOD is subsequently decomposed by catalase (see graphical abstract).

Besides antioxidant enzymes, molecular antioxidants also play an important role in reducing oxidative stress. They involve vitamins, carotenoids and flavonoids, for instance [87]. Supplementation from certain foods is feasible, however, their activity in ROS decomposition lags behind the enzymatic antioxidants. Non-enzymatic routes are also established to estimate antioxidant capacity. Methods based on free radicals involve 2,2-diphenyl-1-picrylhydrazyl (DPPH) [88], nitrogen monoxide (NO) [89], radical form of 2,2' -azino-bis(3-ethylbenzthiazoline-6-sulfonic acid) $\left(\mathrm{ABTS}^{+}\right)$[90] and peroxynitrite ion $\left(\mathrm{ONOO}^{-}\right.$, prepared by the direct, cold peroxidation of nitrite salts) [91], which are relatively stable and can be reduced by the antioxidant of choice.

In addition, Fenton reaction, which is a catalytic route to decompose $\mathrm{H}_{2} \mathrm{O}_{2}$ in the presence of metal ions, especially $\mathrm{Fe}^{2+}$ or $\mathrm{Fe}^{3+}$, generating aggressive $\mathrm{OH} \cdot$ and $\mathrm{OOH} \cdot$ radicals, therefore used for strong oxidations and thus, it is a radical source to probe enzymatic antioxidant compounds [92]. Two indirect radical-based tests include thiobarbituric acid (TBA) as substrate [93]. The degradation of 2-deoxyribose by Fenton reaction [94] and egg lipid peroxidation [95] produces small dialdehydes, mainly malondialdehyde that gives a colored condensation product with TBA. If $\mathrm{OH} \cdot$ radicals in Fenton kinetics or the lipid damaging radicals are consumed by antioxidants, the color in the reactions with TBA are less profound. Further, two assays take oxidative metal complexes as reagents with $\mathrm{Fe}^{3+}$ (Ferric reducing antioxidant power assay (FRAP) [96], with 2,4,6-tris(2-pyridyl)-s-triazine ligand) and $\mathrm{Cu}^{2+}$ (cupric reducing antioxidant capacity (CUPRAC) assay [97], with 2,9-dimethyl-1,10-phenanthroline ligand) central ions. The latter test has a kinetic advantage as the $\mathrm{Cu}^{2+}$ complex is easier to reduce. For detailed antioxidant effect of various materials, the reader is referred to the works of Nimse and Pal [98] and Valgimigli et al. [99].

Due to the increased harmful environmental effects such as air pollution, food additives and radiations, the ROS level increased and thus, oxidative stress became an important issue nowadays. The supplementation of the above natural antioxidants is complicated due to their high sensitivity to the environmental conditions (enzymatic) or limited water solubility (molecular). Therefore, their heterogenization in composite materials, which provides sufficient protection and solubilization of the antioxidants, is a promising research direction.

\section{Metal Oxide Structures}

\subsection{Cobalt-Based 2D Oxides}

The intrinsic peroxidase and catalase activity of $\mathrm{Co}_{3} \mathrm{O}_{4}$ was first described in 2012 for cubic nanoparticles [100] (NPs) and was proven at several occasions for spherical NPs [101] and architectures consisting of $\mathrm{Co}_{3} \mathrm{O}_{4}$ nanorods [102]. Morphology-dependent study was also conducted, revealing an order of nanocubes $<$ nanorods $<$ nanoplates (Figure 2) in catalytic activity, pointing out that the efficiency depends on the most exposed crystal plane [103]. The same correlation was found by Zhang et al. who were able to produce polyhedrons of $\mathrm{Co}_{3} \mathrm{O}_{4}$, possessing approximately $55 \%$ of peroxidase and $70-80 \%$ of catalase activity, compared to the 2D platelets [104]. Data of the quantitative assessment of the activity, together with other $2 \mathrm{D}$ antioxidant systems discussed in this feature article, are given in Table 1. 
Table 1. Two-dimensional 2D nanomaterials of antioxidant properties and the quantitative assessment of their activities in test reactions.

\begin{tabular}{|c|c|c|c|c|c|}
\hline Materials & $\begin{array}{l}\text { Mimicked } \\
\text { Enzymes }\end{array}$ & \multicolumn{3}{|c|}{ Activity Assessment ${ }^{\text {a }}$} & Ref. \\
\hline $\begin{array}{c}\text { Cu(4-hydroxythiophenol) } \\
\text { Nanosheets }\end{array}$ & Peroxidase & \multicolumn{3}{|c|}{$\begin{array}{c}\mathrm{K}_{\mathrm{m}}(\mathrm{mM}) \\
0.716 \\
0.431\end{array}$} & [19] \\
\hline $\mathrm{MoS}_{2}$ Nanosheets & Peroxidase & $\mathrm{H}_{2} \mathrm{O}_{2}$ & $\begin{array}{c}\mathrm{K}_{\mathrm{m}}(\mathrm{mM}) \\
0.003\end{array}$ & $\begin{array}{c}\mathrm{v}_{\max }\left(10^{-6}\right. \\
\mathrm{mol} / \mathrm{min}) \\
3.4\end{array}$ & [39] \\
\hline $\begin{array}{c}\mathrm{Mg} / \mathrm{Al}-\mathrm{CO}_{3}-\mathrm{LDH}-\mathrm{SOD} \\
\mathrm{Mg} / \mathrm{Al}-\mathrm{CO}_{3}-\mathrm{LDH}-\mathrm{SOD}-\mathrm{Hep}\end{array}$ & SOD & $\begin{array}{l}\text { Fridovich } \\
\text { method }^{b}\end{array}$ & \multicolumn{2}{|c|}{$\begin{array}{c}\mathrm{IC}_{50}(\mathrm{mg} / \mathrm{L})^{\mathrm{c}} \\
0.056 \\
0.096\end{array}$} & [60] \\
\hline SOD-PDADMAC-TNS & SOD & $\begin{array}{l}\text { Fridovich } \\
\text { method }^{b}\end{array}$ & \multicolumn{2}{|c|}{$\begin{array}{l}\mathrm{IC}_{50}(\mathrm{mg} / \mathrm{L}) \\
0.057\end{array}$} & [61] \\
\hline $\mathrm{Co}_{3} \mathrm{O}_{4}$ Sisal-like Structures & Peroxidase & $\begin{array}{l}\mathrm{H}_{2} \mathrm{O}_{2} \\
\text { TMB }\end{array}$ & \multicolumn{2}{|c|}{$\begin{array}{c}\mathrm{K}_{\mathrm{m}}(\mathrm{mM}) \\
0.827 \\
0.015\end{array}$} & [102] \\
\hline $\mathrm{Co}_{3} \mathrm{O}_{4}$ Nanoplates & Peroxidase & $\begin{array}{c}\mathrm{H}_{2} \mathrm{O}_{2} \\
\mathrm{TMB}\end{array}$ & $\begin{array}{c}\mathrm{K}_{\mathrm{m}}(\mathrm{mM}) \\
284 \\
0.090\end{array}$ & $\begin{array}{c}\mathrm{v}_{\max }\left(10^{-8} \mathrm{M} / \mathrm{s}\right) \\
48.1 \\
9.9\end{array}$ & [103] \\
\hline $\mathrm{Co}_{3} \mathrm{O}_{4}$ Nanoplates & Peroxidase & $\begin{array}{l}\text { Fixed TMB and } \\
\qquad \mathrm{H}_{2} \mathrm{O}_{2}\end{array}$ & \multicolumn{2}{|c|}{$\begin{array}{c}\mathrm{v} \\
0.038 \text { a.u./s }\end{array}$} & [104] \\
\hline $\mathrm{Co}_{3} \mathrm{O}_{4}$ Microbelts & Peroxidase & $\begin{array}{c}\mathrm{H}_{2} \mathrm{O}_{2} \\
\mathrm{TMB}\end{array}$ & \multicolumn{2}{|c|}{$\begin{array}{c}\mathrm{K}_{\mathrm{m}}(\mathrm{mM}) \\
0.0262 \\
0.012\end{array}$} & [105] \\
\hline $\mathrm{Co}_{3} \mathrm{O}_{4}-\mathrm{CeO}_{2}$ Nanosheets & Peroxidase & $\begin{array}{c}\mathrm{H}_{2} \mathrm{O}_{2} \\
\mathrm{TMB}\end{array}$ & $\begin{array}{c}\mathrm{K}_{\mathrm{m}}(\mathrm{mM}) \\
132.2 \\
0.36\end{array}$ & $\begin{array}{c}\mathrm{v}_{\max }\left(10^{-8} \mathrm{M} / \mathrm{s}\right) \\
4.3 \\
16.7\end{array}$ & [106] \\
\hline $\mathrm{Co}_{3} \mathrm{O}_{4}$ Nanosheets & Peroxidase & $\begin{array}{c}\mathrm{H}_{2} \mathrm{O}_{2} \\
\mathrm{TMB}\end{array}$ & $\begin{array}{c}\mathrm{K}_{\mathrm{m}}(\mathrm{mM}) \\
2.22 \\
0.082\end{array}$ & $\begin{array}{c}\mathrm{v}_{\max }\left(10^{-8} \mathrm{M} / \mathrm{s}\right) \\
11.8 \\
6.6\end{array}$ & [107] \\
\hline $\mathrm{V}_{2} \mathrm{O}_{5}$ nanosheets & $\begin{array}{l}\text { Glutathione } \\
\text { Peroxidase }\end{array}$ & $\begin{array}{c}\mathrm{GSH} \\
\mathrm{H}_{2} \mathrm{O}_{2}\end{array}$ & $\begin{array}{c}\mathrm{K}_{\mathrm{m}}(\mathrm{mM}) \\
3.425 \\
0.0573\end{array}$ & $\begin{array}{c}\mathrm{v}_{\max }\left(10^{-8} \mathrm{M} / \mathrm{s}\right) \\
778.8 \\
388.5\end{array}$ & [108] \\
\hline $\mathrm{VO}_{2}$ Nanosheets & Peroxidase & $\begin{array}{l}\mathrm{H}_{2} \mathrm{O}_{2} \\
\mathrm{TMB}\end{array}$ & $\begin{array}{c}\mathrm{K}_{\mathrm{m}}(\mathrm{mM}) \\
2.924 \\
0.111\end{array}$ & $\begin{array}{c}\mathrm{V}_{\max }\left(10^{-8} \mathrm{M} / \mathrm{s}\right) \\
97300 \\
16800\end{array}$ & [109] \\
\hline $\begin{array}{l}\text { HRP-Titanate Nanosheets } \\
\text { SOD-Titanate Nanosheets }\end{array}$ & HRP & $\begin{array}{l}\text { Guaiacol } \\
\text { Hypoxanthine/XO } \\
\text { Cytochrome c }\end{array}$ & $\begin{array}{c}\mathrm{K}_{\mathrm{m}}(\mathrm{mM}) \\
2.06 \\
\mathrm{IC}_{50}(\mathrm{U}) \\
0.036\end{array}$ & $\begin{array}{c}\mathrm{v}_{\max }\left(10^{-8} \mathrm{M} / \mathrm{s}\right) \\
176\end{array}$ & [110] \\
\hline $\begin{array}{c}\text { HPR-TiO }_{x} \\
\text { nanosheets-magnetic beads }\end{array}$ & HRP & Guaiacol & $\begin{array}{c}\mathrm{K}_{\mathrm{m}}(\mathrm{mM}) \\
1.8\end{array}$ & $\begin{array}{c}\mathrm{v}_{\max }\left(10^{-8} \mathrm{M} / \mathrm{s}\right) \\
330\end{array}$ & [111] \\
\hline Au-MoS 2 Nanoribbons & Peroxidase & $\begin{array}{c}\mathrm{H}_{2} \mathrm{O}_{2} \\
\mathrm{TMB}\end{array}$ & $\begin{array}{c}\mathrm{K}_{\mathrm{m}}(\mathrm{mM}) \\
10 \\
0.015\end{array}$ & $\begin{array}{c}\mathrm{v}_{\max }\left(10^{-8} \mathrm{M} / \mathrm{s}\right) \\
1170 \\
670\end{array}$ & [112] \\
\hline $\mathrm{MoS}_{\mathrm{x}}-\mathrm{Co}(\mathrm{OH})_{2}$ Nanoflakes & Peroxidase & $\begin{array}{c}\mathrm{H}_{2} \mathrm{O}_{2} \\
\mathrm{TMB}\end{array}$ & $\begin{array}{c}\mathrm{K}_{\mathrm{m}}(\mathrm{mM}) \\
0.127 \\
0.236\end{array}$ & $\begin{array}{c}\mathrm{v}_{\max }\left(10^{-8} \mathrm{M} / \mathrm{s}\right) \\
8.73 \\
5.69\end{array}$ & [113] \\
\hline $\mathrm{MoSe}_{2}$ Nanosheets & Peroxidase & $\begin{array}{c}\mathrm{H}_{2} \mathrm{O}_{2} \\
\mathrm{TMB}\end{array}$ & $\begin{array}{c}\mathrm{K}_{\mathrm{m}}(\mathrm{mM}) \\
0.155 \\
0.014\end{array}$ & $\begin{array}{c}\mathrm{V} \max \left(10^{-8} \mathrm{M} / \mathrm{s}\right) \\
0.99 \\
0.56\end{array}$ & [114] \\
\hline VS $_{2}$ Nanosheets & Peroxidase & $\begin{array}{c}\mathrm{H}_{2} \mathrm{O}_{2} \\
\mathrm{TMB}\end{array}$ & $\begin{array}{c}\mathrm{K}_{\mathrm{m}}(\mathrm{mM}) \\
3.49 \\
0.28\end{array}$ & $\begin{array}{c}\mathrm{v}_{\max }\left(10^{-8} \mathrm{M} / \mathrm{s}\right) \\
55.7 \\
41.6\end{array}$ & [115] \\
\hline Cu-Boron Nitride Nanosheets & Peroxidase & $\begin{array}{c}\mathrm{H}_{2} \mathrm{O}_{2} \\
\mathrm{TMB}\end{array}$ & $\begin{array}{c}\mathrm{K}_{\mathrm{m}}(\mathrm{mM}) \\
25 \\
0.175\end{array}$ & $\begin{array}{c}\mathrm{v}_{\max }\left(10^{-8} \mathrm{M} / \mathrm{s}\right) \\
12.5 \\
3.76\end{array}$ & [116] \\
\hline Ni-MOF Nanosheets & HRP & $\begin{array}{l}\mathrm{H}_{2} \mathrm{O}_{2} \\
\mathrm{TMB}\end{array}$ & $\begin{array}{c}\mathrm{K}_{\mathrm{m}}(\mathrm{mM}) \\
2.49 \\
0.365\end{array}$ & $\begin{array}{c}\mathrm{v}_{\max }\left(10^{-8} \mathrm{M} / \mathrm{s}\right) \\
130 \\
6.53\end{array}$ & [117] \\
\hline
\end{tabular}


Table 1. Cont.

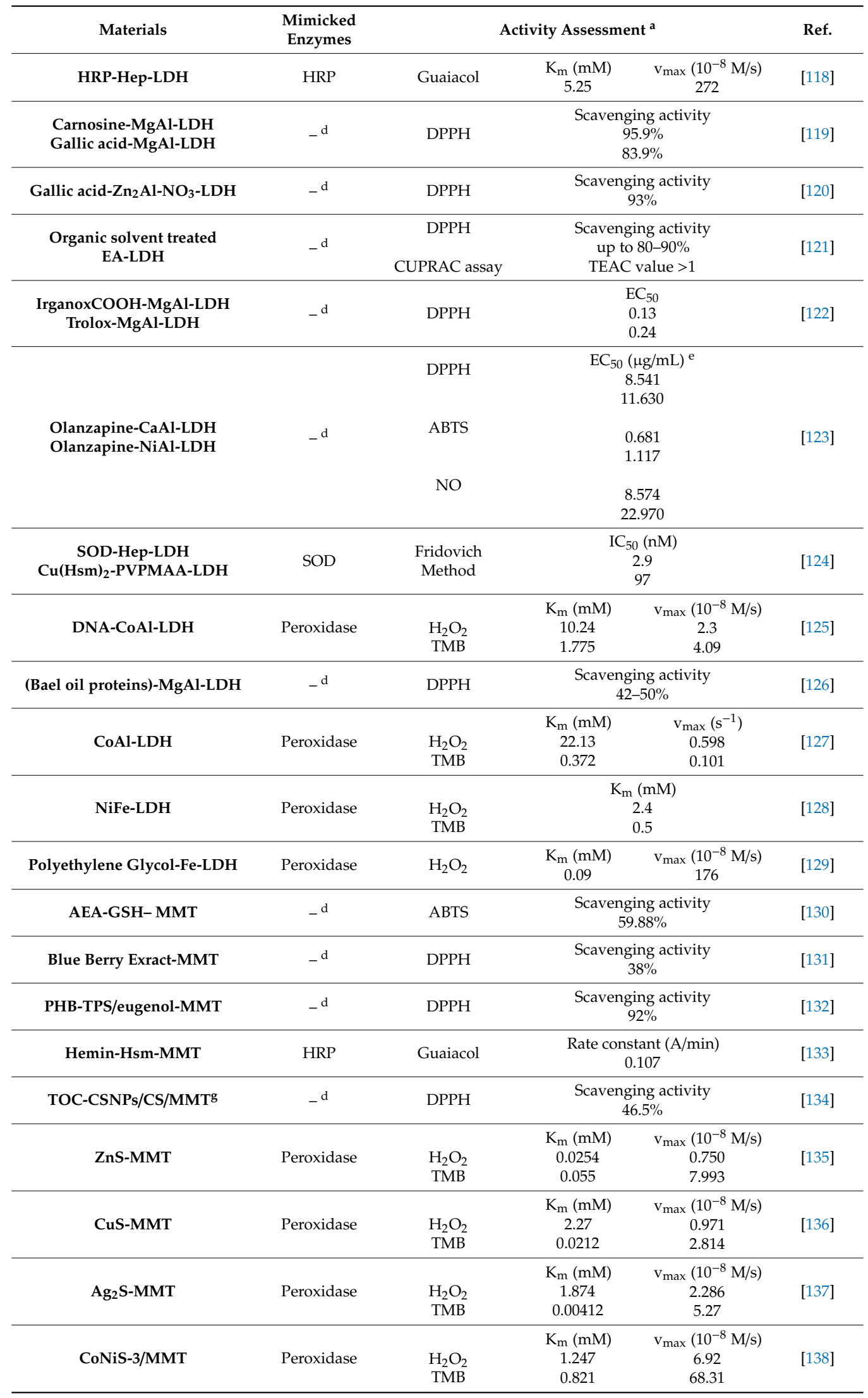


Table 1. Cont.

\begin{tabular}{|c|c|c|c|c|c|}
\hline Materials & $\begin{array}{l}\text { Mimicked } \\
\text { Enzymes }\end{array}$ & & ity Assessm & & Ref. \\
\hline HRP-MMT & HRP & Phenol & $\begin{array}{c}\mathrm{K}_{\mathrm{m}}(\mathrm{mM}) \\
12.96\end{array}$ & $\begin{array}{c}\mathrm{v}_{\max }\left(10^{-8} \mathrm{M} / \mathrm{s}\right) \\
7150\end{array}$ & [139] \\
\hline $\mathrm{Cu}-\mathrm{Zn}$ complex-MMT & SOD & $\begin{array}{l}\text { Fridovich } \\
\text { method }^{b}\end{array}$ & \multicolumn{2}{|c|}{$\begin{array}{c}\mathrm{IC}_{50}(\mu \mathrm{M}) \\
91.0\end{array}$} & {$[140]$} \\
\hline Cu-histidine-MMT & SOD & $\begin{array}{l}\text { Fridovich } \\
\text { method }^{b}\end{array}$ & \multicolumn{2}{|c|}{$\begin{array}{l}\mathrm{IC}_{50}(\mu \mathrm{M}) \\
251\end{array}$} & [141] \\
\hline Ni Foam-CoP Nanosheets & Peroxidase & $\begin{array}{l}\mathrm{H}_{2} \mathrm{O}_{2} \\
\mathrm{TMB}\end{array}$ & \multicolumn{2}{|c|}{$\begin{array}{c}\mathrm{K}_{\mathrm{m}}(\mathrm{mM}) \\
4.90 \\
0.54\end{array}$} & [142] \\
\hline $\begin{array}{c}\mathrm{Co}_{2}(\mathrm{OH})_{2} \mathrm{CO}_{3}-\mathrm{CeO}_{2} \\
\text { Nanosheets }\end{array}$ & Peroxidase & $\begin{array}{l}\mathrm{H}_{2} \mathrm{O}_{2} \\
\mathrm{TMB}\end{array}$ & $\begin{array}{c}\mathrm{K}_{\mathrm{m}}(\mathrm{mM}) \\
10.01 \\
0.14\end{array}$ & $\begin{array}{c}\mathrm{V}_{\max }\left(10^{-8} \mathrm{M} / \mathrm{s}\right) \\
10.21 \\
20.14\end{array}$ & [143] \\
\hline $\mathrm{Fe}_{3}\left(\mathrm{PO}_{4}\right)_{2} \cdot 8 \mathrm{H}_{2} \mathrm{O}$ Nanoflowers & Peroxidase & $\begin{array}{l}\mathrm{H}_{2} \mathrm{O}_{2} \\
\text { TMB }\end{array}$ & $\begin{array}{c}\mathrm{K}_{\mathrm{m}}(\mathrm{mM}) \\
0.11 \\
0.36\end{array}$ & $\begin{array}{c}\mathrm{v}_{\max }\left(10^{-7} \mathrm{M} / \mathrm{s}\right) \\
5.58 \\
1.58\end{array}$ & [144] \\
\hline Porous Iron Oxide Nanoflakes & Peroxidase & $\begin{array}{l}\mathrm{H}_{2} \mathrm{O}_{2} \\
\mathrm{TMB}\end{array}$ & $\begin{array}{c}\mathrm{K}_{\mathrm{m}}(\mathrm{mM}) \\
150.47 \\
0.24\end{array}$ & $\begin{array}{c}\mathrm{v}_{\max }\left(10^{-8} \mathrm{M} / \mathrm{s}\right) \\
3.12 \\
3.07\end{array}$ & [145] \\
\hline
\end{tabular}

a The columns contain the applied substrate or assay and the quantitative measure of the activity; ${ }^{\mathrm{b}}$ The method is described in reference [84]; ${ }^{c}$ Concentration of enzyme or enzyme mimic necessary to decompose $50 \%$ of the radicals forming in the test reaction; ${ }^{\mathrm{d}}$ General radical scavenging activity was assessed, no enzymatic assays was applied; e Top values belong to olanzapine-CaAl-LDH and the bottom ones to olanzapine-NiAl-LDH. Abbreviation list: TMB: 3,3',5,5'-tetramethylbenzidine, SOD: superoxide dismutase, GSH: glutathione, HRP: horseradish peroxidase, XO: xanthine oxidase, DPPH: 2,2-diphenyl-1-picrylhydrazyl, CUPRAC: cupric reducing antioxidant capacity, ABTS: 2,2'-azino-bis(3-ethylbenzthiazoline-6-sulfonic acid).
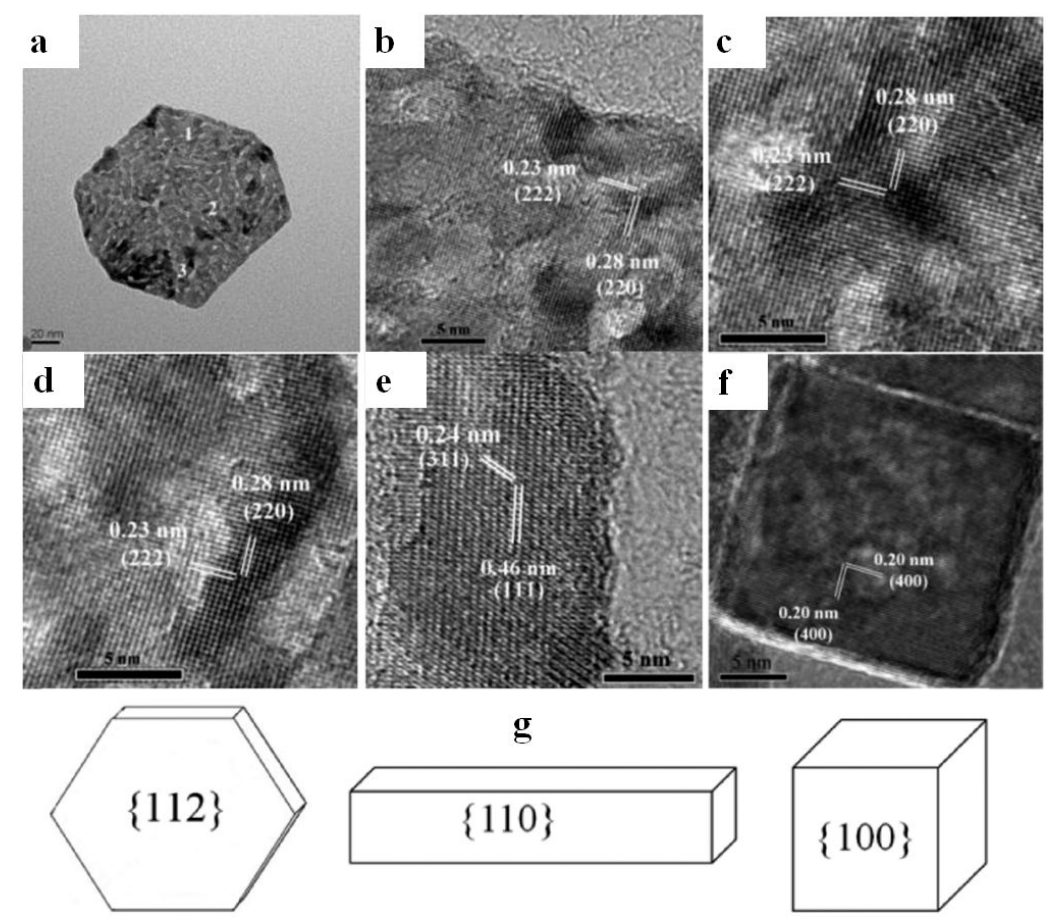

Figure 2. TEM image of a typical $\mathrm{Co}_{3} \mathrm{O}_{4}$ nanoplate (a), high-resolution transmission electron microscopy (HRTEM) images of site 1 (a), site 2 (c) and site $3(\mathbf{d})$ of $\mathrm{Co}_{3} \mathrm{O}_{4}$ nanoplate, a HRTEM image of a $\mathrm{Co}_{3} \mathrm{O}_{4}$ nanorod (e), a HRTEM image of $\mathrm{a} \mathrm{Co}_{3} \mathrm{O}_{4}$ nanocube (f) and exposed crystal planes on the nanoplate, nanorod and nanocube of $\mathrm{Co}_{3} \mathrm{O}_{4}(\mathrm{~g})$. Reproduced from Reference [103] with permission from the PCCP Owner Societies.

Elongated $2 \mathrm{D} \mathrm{Co}_{3} \mathrm{O}_{4}$ belts were obtained by electrospinning technique from $\mathrm{Co}\left(\mathrm{NO}_{3}\right)_{2}$ containing polyvinylpyrollidone gel with superior affinity compared to the native horseradish peroxidase (HRP) 
enzyme and up to 100-fold higher activity was calculated from the Michaelis constants $\left(\mathrm{K}_{\mathrm{m}}\right)$ determined in the test reactions involving $\mathrm{H}_{2} \mathrm{O}_{2}$ and $\mathrm{TMB}\left(3,3^{\prime}, 5,5^{\prime}\right.$-tetramethylbenzidine). Besides, the belts were found to be stable at significantly higher temperature than HRP [105]. The high-resolution transmission electron microscopy (HRTEM) images of the belts obtained reflect characteristic basal distances of 0.24 and $0.29 \mathrm{~nm}$ assigned to (311) and (220) interplanar spacings in $\mathrm{Co}_{3} \mathrm{O}_{4}$, respectively.

Platelets of $\mathrm{Co}_{3} \mathrm{O}_{4}$ were combined with $\mathrm{CeO}_{2}$ sheets to a nanocomposite of relatively low affinity towards $\mathrm{H}_{2} \mathrm{O}_{2}$, as indicated by higher $\mathrm{K}_{\mathrm{m}}$ values, but excellent maximum reaction rate $\left(v_{\max }\right)$ was observed in the diffusion controlled regime [106]. Separately, both oxides are considered as peroxidase nanozymes that was reinforced in the composite, which was later used as a paper based analytical glucose sensor with smartphone software quantification.

In a recent finding, porous $\mathrm{Co}_{3} \mathrm{O}_{4}$ nanoplates of $\mathrm{pH}$-switchable peroxidase-like (acidic medium) or catalase-like (basic medium) properties was synthesized [107]. Overall, the porous flakes possessed remarkable kinetic parameters and were used as a glucose sensor enabled by glucose oxidase (GOx)-glucose selective reaction (Figure 3).

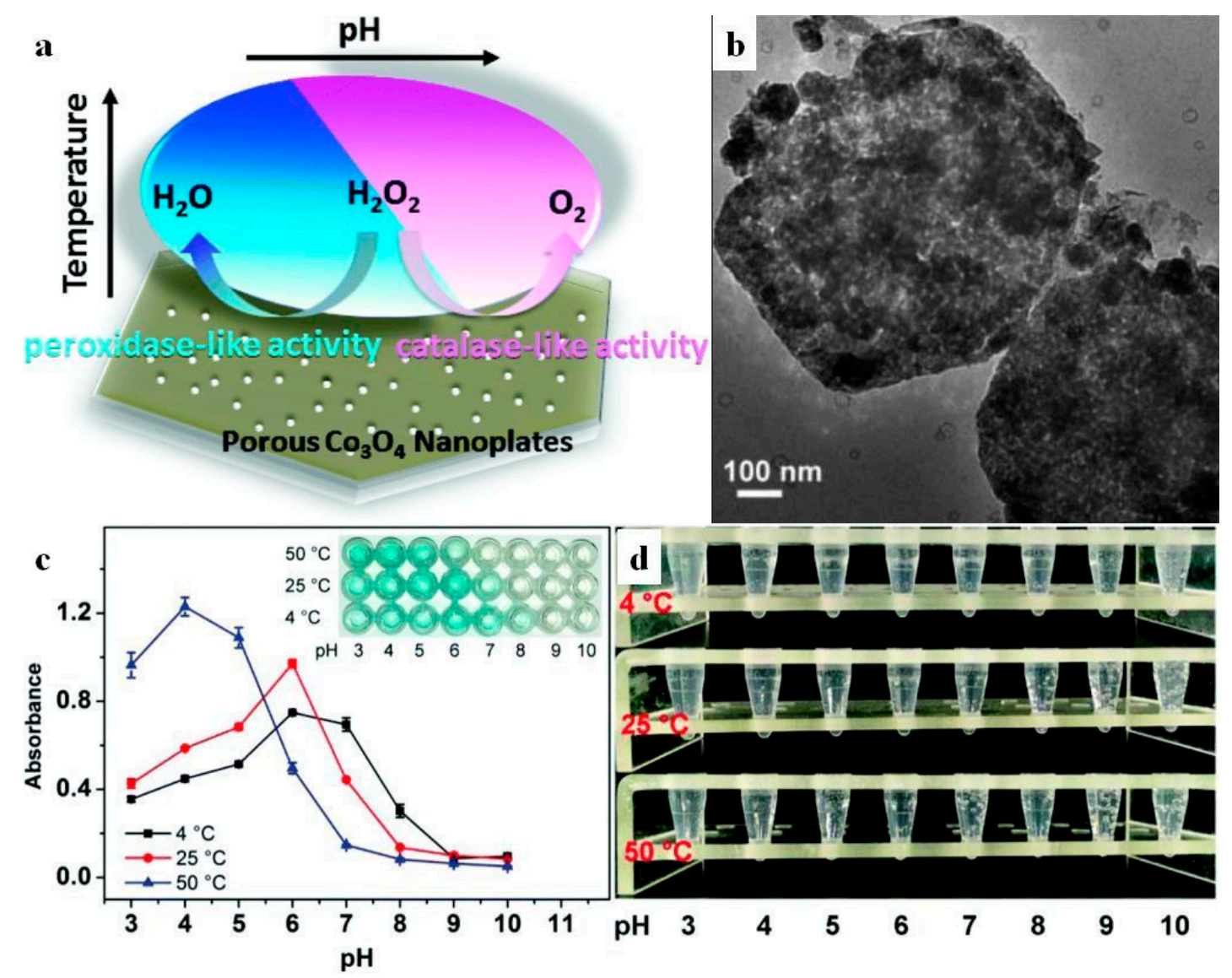

Figure 3. Schematic representation of the multienzymatic activity of porous $\mathrm{Co}_{3} \mathrm{O}_{4}$ flakes (a) captured on TEM micrograph (b), the peroxidase activity of the nanoflakes in TMB assay with visual representation as inset photograph (c) and its $\mathrm{O}_{2}$ evolution through catalase activity (d). Reproduced from Reference [107] with permission from the Royal Society of Chemistry.

Finally, a mixed-valance state lamellar cobalt oxide with non-stoichiometric composition was also used as a nanozyme to oxidize TMB substrate with molecular $\mathrm{O}_{2}$ [146]. This structure was synthesized by partial oxidation of $\mathrm{Co}(\mathrm{II})$-trimesate and was applied as a glutathione (GSH) sensor. 


\subsection{Vanadium-Based Oxides}

Ghosh et al. extensively examined the morphology-activity correlation of orthorhombic $\mathrm{V}_{2} \mathrm{O}_{5}$ structures of peroxidase activity [108]. Unlike $\mathrm{Co}_{3} \mathrm{O}_{4}$ [104], they found that surface area is not a main factor in activity, but it is the accessibility of active sites on the dominant crystal faces. The GSH-mediated peroxidase activity and surface area of the nanomaterials obtained are depicted in Figure 4 (with $\mathrm{V}_{2} \mathrm{O}_{5}$ abbreviated as $\mathrm{V}$ ), showing that $\mathrm{V}_{2} \mathrm{O}_{5}$ spheres reached the highest maximum rate, followed by flowers, sheets and wires, out of which only wires and 2D sheets are saturated at the lowest $\mathrm{H}_{2} \mathrm{O}_{2}$ concentration.

a

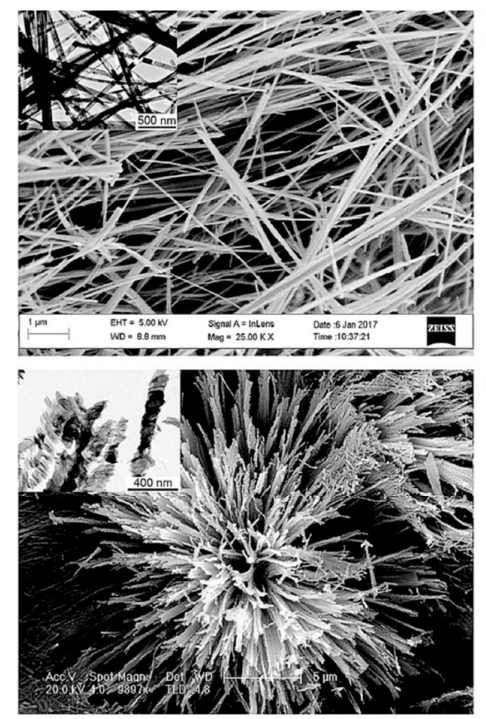

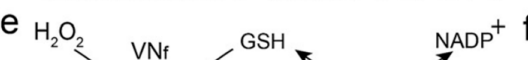

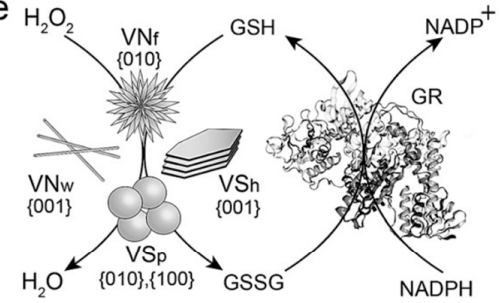

g

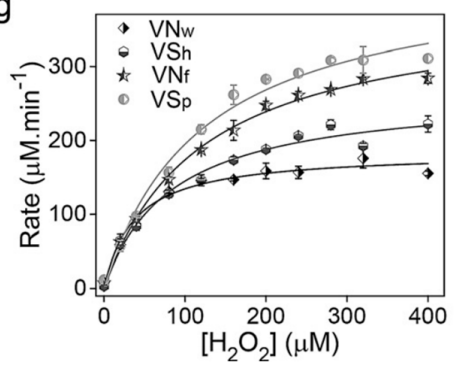

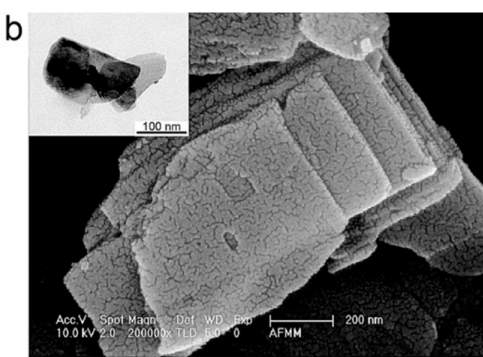
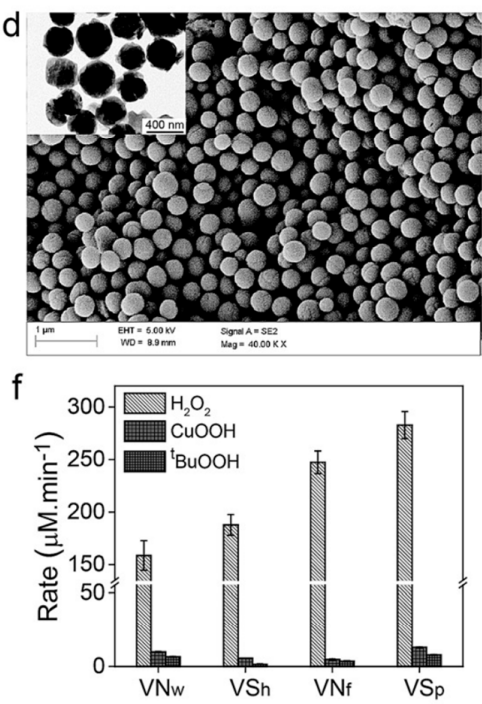

h

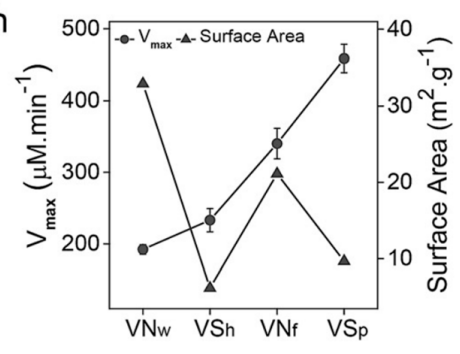

Figure 4. SEM and TEM (inset) images of $\mathrm{V}_{2} \mathrm{O}_{5}$ nanowires $\left(\mathrm{V}_{\mathrm{Nw}}\right)(\mathbf{a}), \mathrm{V}_{2} \mathrm{O}_{5}$ sheets $\left(\mathrm{V}_{\mathrm{Sh}}\right)(\mathbf{b})$, $\mathrm{V}_{2} \mathrm{O}_{5}$ nanoflowers $\left(\mathrm{V}_{\mathrm{Nf}}\right)$ (c) and $\mathrm{V}_{2} \mathrm{O}_{5}$ spheres $\left(\mathrm{V}_{\mathrm{Sp}}\right)\left(\right.$ d). Reduction of $\mathrm{H}_{2} \mathrm{O}_{2}$ by GSH in the presence of nanomaterials, glutathione reductase (GR) and NADPH (e). The GSH peroxidase-like activity using $\mathrm{H}_{2} \mathrm{O}_{2}$, tert-butyl hydroperoxide (t-BuOOH) and cumene hydroperoxide $(\mathrm{CuOOH})(\mathbf{f})$. Michaelis-Menten plot for the nanozymes (g). Trends in $v_{\max }$ and surface area (h). Copyright (2020) Wiley. Used with permission from (Ghosh, S.; Roy, P.; Karmodak, N.; Jemmis, E.D.; Mugesh, G. Nanoisozymes: Crystal-facet-dependent enzyme-mimetic activity of $\mathrm{V}_{2} \mathrm{O}_{5}$ nanomaterials. Angew. Chem. Int. Ed. 2018, 57, 4510-4515) Reference [108]. 
Aside from its peroxidase mimic, a layered $\mathrm{V}_{2} \mathrm{O}_{5}$ 2D structure was also used to detect GSH via an oxidase-type mechanism [147]. Lower valence state vanadium oxide, $\mathrm{VO}_{2}$ was investigated in various morphologies [109]. Fibrillar, lamellar and elongated NPs were tested against TMB substrate and it was pointed out that $\mathrm{VO}_{2}$ sheets exhibited the best kinetic overall parameters in regard of $\mathrm{K}_{\mathrm{m}}$ and $\mathrm{v}_{\max }$. Additionally, the aforementioned $\mathrm{VO}_{2}$ particles were applied as $\mathrm{H}_{2} \mathrm{O}_{2}$ sensors with the nanosheets providing linear range up to $62.5 \mathrm{mM} \mathrm{H}_{2} \mathrm{O}_{2}$, four times higher than the second best performing nanorods.

\subsection{Titania-Based Composites}

The prominent photocatalytic activity of pure and doped $\mathrm{TiO}_{2}$ is known for decades [4]. Despite $\mathrm{Ti}(\mathrm{IV})$ is moderately redox active, $\mathrm{TiO}_{2}$ is not an antioxidant nanozyme. However, its negative surface charge in a broad range of $\mathrm{pH}$ makes it a suitable vehicle for HRP immobilization, for instance. Xie et al., constructed hollow titania spheres based on sheets as building blocks, capable storing 20 mass $\%$ HRP owing to the porous structure [148]. This highly loaded material was used for electrochemical $\mathrm{H}_{2} \mathrm{O}_{2}$ sensing with linearity over three orders of magnitudes.

Moreover, titania materials were proved as excellent solid supports for other antioxidant enzymes due to their biocompatibility, high abundance of surface functionalities and chemical inertness. Surface modifications with polyelectrolytes resulted in stable structures capable of hosting various enzymes. Accordingly, lamellar titania nanosheet (TNS)-based nanocomposite with this setup had peroxidase activity nearly identical to the bare HRP (Figure 5) [149]. An adsorbed positively charged poly(diallyldimethylammonium chloride) (PDADMAC) polyelectrolyte layer improved the enzyme's structural integrity over longer timeframes and maintained a good colloidal stability for the platelets.

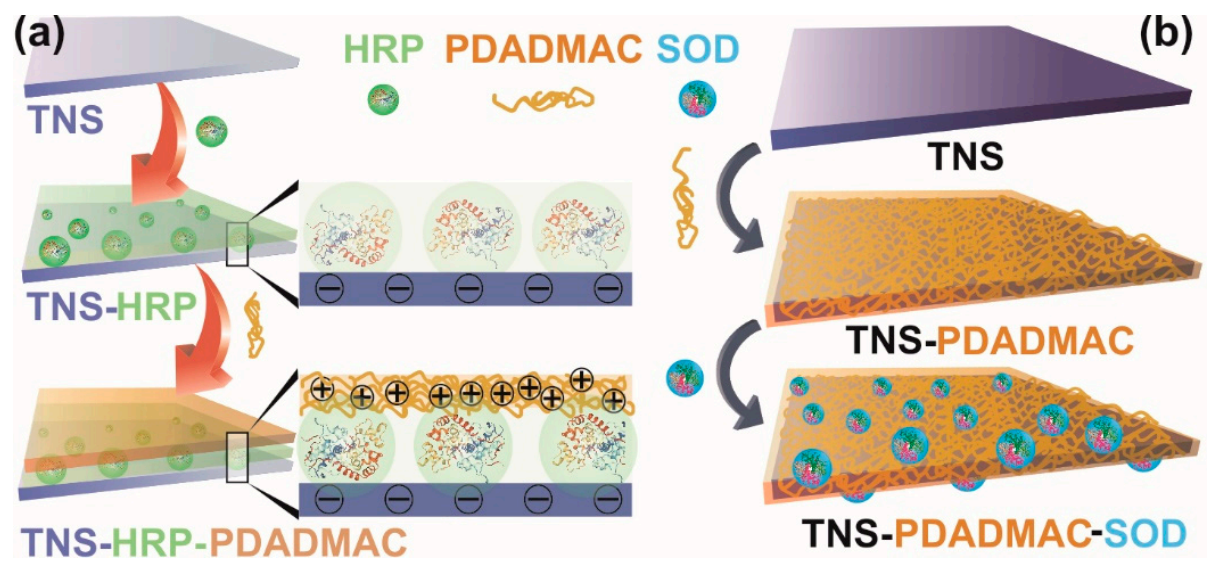

Figure 5. Illustration of HRP (a) and SOD (b) immobilization on titania nanosheet (TNS) of saturated poly(diallyldimethylammonium chloride (PDADMAC) polyelectrolyte layer on the surface. Reprinted with permission from (Rouster, P.; Pavlovic, M.; Saringer, S.; Szilagyi, I. Functionalized titania nanosheet dispersions of peroxidase activity. J. Phys. Chem. C 2018, 122, 11455-11463) Reference [149]. Copyright (2020) American Chemical Society (a). Copyright (2020) Wiley. Used with permission from (Rouster, P.; Pavlovic, M.; Szilagyi, I. Immobilization of superoxide dismutase on polyelectrolyte functionalized titania nanosheets. ChemBiochem 2018, 19, 404-410) Reference [61] (b).

The same TNS was used to immobilize SOD enzyme [61]. Surface functionalization was carried out first with PDADMAC to obtain positively charged sheets and the enzyme was attached through electrostatic and hydrophobic interactions. The same superoxide anion radical scavenging activity of the free and attached SOD indicated that the enzyme kept its structural integrity upon immobilization.

Kamada et al. demonstrated that nanometric titanate nanosheets enhanced the catalytic properties of aqueous HRP and SOD [110]. It was claimed that TNS served as a surfactant and helped to decrease the number of HRP and SOD aggregates in the solution, exposing more catalytic centers for the 
reactions to occur. This was possible due to electrostatic attraction, thus immobilization of the enzymes on TNS particles, as indicated by dynamic light scattering measurements.

Stable suspensions were obtained by immobilizing HRP and magnetic beads on positively charged layered titania in slightly acidic samples [111]. Although steric hindrance and possibly slight conformational changes led to reduced HRP activity, the magnetic composite was separable with strong magnets at the end of catalytic cycles. Furthermore, the reused material maintained $80 \%$ of its original activity after 5 repetitions.

\section{Chalcogenide Structures}

Among the other lamellar chalcogenides, molybdenum compounds were inspected thoroughly. Pure $\mathrm{MoS}_{2}$ has multienzymatic activity under physiological conditions. It was reported to have the ability to scavenge superoxide radicals generated by the xanthine/xanthine oxidase system and to degrade $\mathrm{H}_{2} \mathrm{O}_{2}$ in catalase and peroxidase-type manners [59]. Although the generation of $\mathrm{OH}$. radicals was evident by using DMPO (5,5-dimethyl-pyrroline $\mathrm{N}$-oxide) as a radical trap for electron paramagnetic resonance (EPR) spectroscopy measurements, the $\mathrm{OH}$ - radical products were transformed to $\mathrm{H}_{2} \mathrm{O}$, proven by the scavenging of Fenton-type developed radicals. Furthermore, the 2D $\mathrm{MoS}_{2}$ was used as a scavenger for other reactive species, e.g., NO and DPPH radicals, meaning that the nanozyme was an excellent oppressor of oxidative stress during in vitro measurements (Figure 6). Moreover, in vivo experiments revealed that $\mathrm{MoS}_{2}$ sheets protected E. coli and S. aureus bacteria from $\mathrm{H}_{2} \mathrm{O}_{2}$-induced oxidative stress. While the nanozyme was fully biocompatible with $E$. coli, it expressed a moderate toxicity on S. aureus.

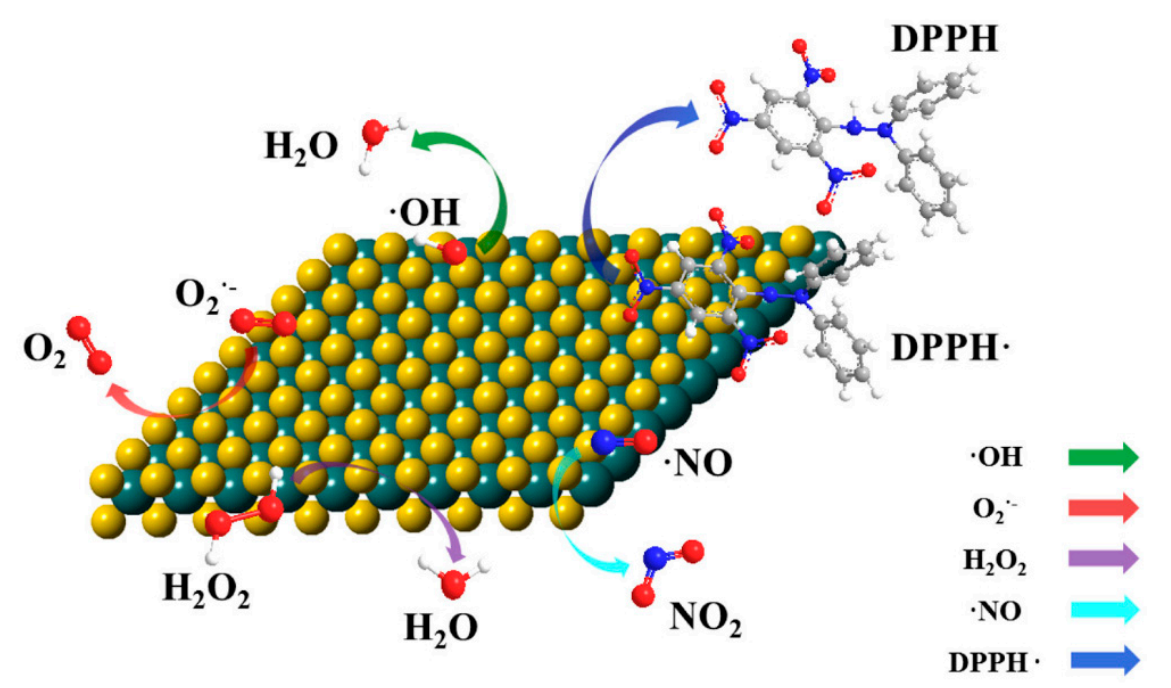

Figure 6. Illustration of the multi-fold antioxidant activity of $\mathrm{MoS}_{2}$ nanosheets. Reprinted with permission from (Chen, T.M.; Zou, H.; Wu, X.J.; Liu, C.C.; Situ, B.; Zheng, L.; Yang, G.W. Nanozymatic antioxidant system based on $\mathrm{MoS}_{2}$ nanosheets. ACS Appl. Mater. Interfaces 2018, 10, 12453-12462) Reference [59]. Copyright (2020) American Chemical Society.

Later, Nandu et al. showed that out of many proteins, lipase selectively masked the peroxidase activity of $2 \mathrm{D} \mathrm{MoS}_{2}$ [39], as indicated by the increasing $\mathrm{K}_{\mathrm{m}}$ values, i.e., decreasing affinity towards $\mathrm{H}_{2} \mathrm{O}_{2}$. The $v_{\max }$ value was also decreased by more than $94 \%$ in the presence of lipase. Based on this principle, the $\mathrm{MoS}_{2}$ NPs were used as a colorimetric lipase sensor.

The peroxidase activity of $\mathrm{MoS}_{2}$ sheets can be improved by depositing Au NPs on the surface to drastically increase reaction rate (100-fold increment in $\mathrm{v}_{\max }$ ) and the affinity to TMB substrate (350-fold decrease in $\mathrm{K}_{\mathrm{m}}$ ) [112]. This system was also used as a probe in detection of free cholesterol.

In another study, $2 \mathrm{D} \mathrm{Co}(\mathrm{OH})_{2}$ flakes were combined with $\mathrm{MoS}_{4}{ }^{2-}$ ions and treated hydrothermally to get a mainly amorphous $\mathrm{CoMo}(\mathrm{OH})_{\mathrm{x}} \mathrm{S}_{\mathrm{y}}$ or simply CoMo hybrid, perceived as $\mathrm{MoS}_{\mathrm{x}}$ doped 
$\mathrm{Co}(\mathrm{OH})_{2}$ [113]. This novel material acted as a tri-enzymatic mimic with catalase, peroxidase and oxidase activity (Figure 7).
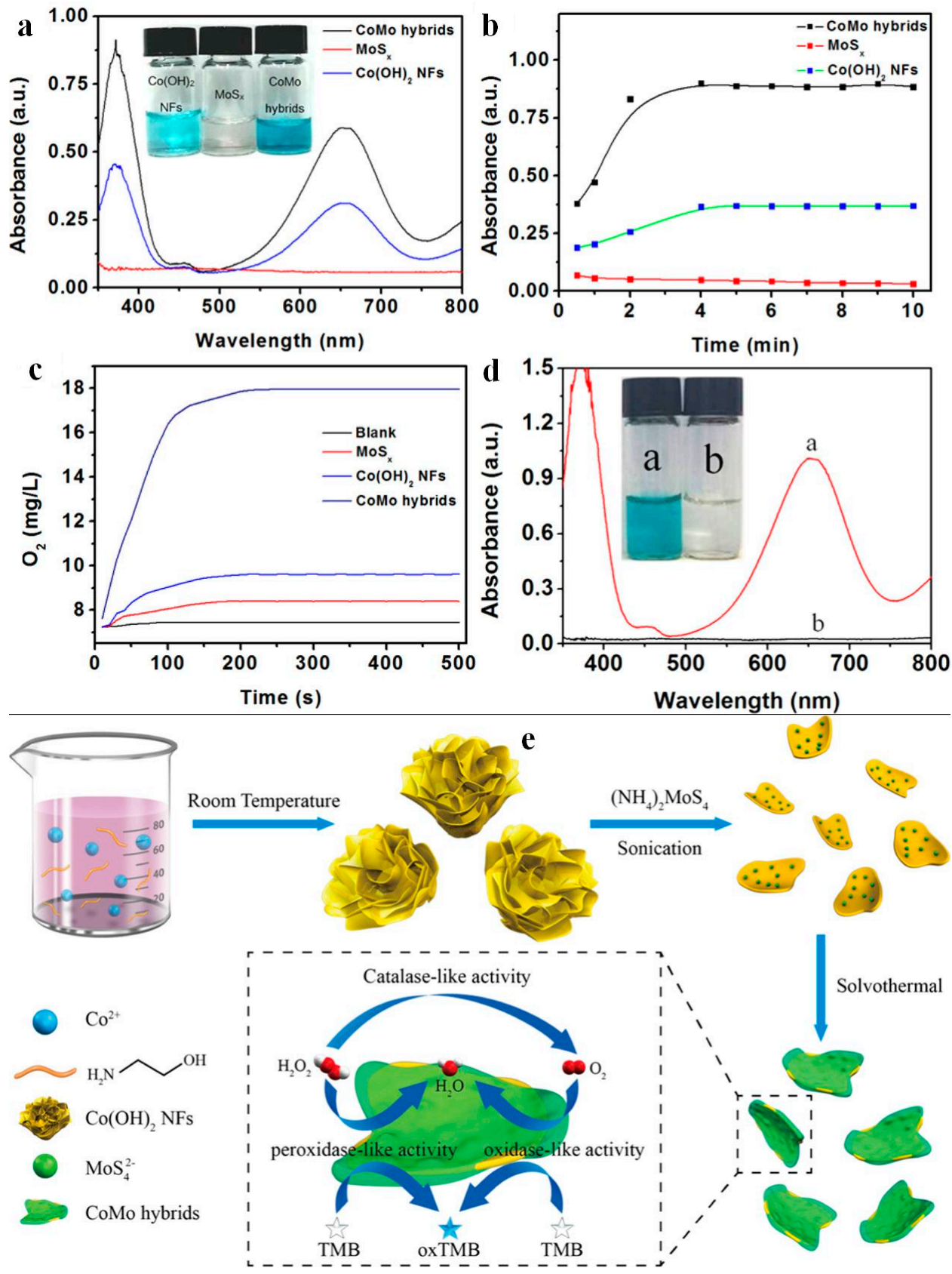

Figure 7. Absorbance intensity of $\mathrm{TMB}$ and $50 \mathrm{mM} \mathrm{H}_{2} \mathrm{O}_{2}$ upon the addition of different materials (a). Time-dependent absorbance of TMB at $652 \mathrm{~nm}$ varied with different catalysts used (b). $\mathrm{O}_{2}$ generation from $\mathrm{H}_{2} \mathrm{O}_{2}$ decomposition with different catalysts (c). Catalytic activity comparison of CoMo hybrids and the supernatant coexisting with the CoMo hybrids (d). Visualized reaction scheme to obtain the CoMo hybrids (e). Reprinted with permission from (Ding, Y.Q.; Wang, G.; Sun, F.Z.; Lin, Y.Q. Heterogeneous nanostructure design based on the epitaxial growth of spongy $\operatorname{MoS}_{x}$ on $2 \mathrm{D} \operatorname{Co}(\mathrm{OH})(2)$ nanoflakes for triple-enzyme mimetic activity: Experimental and density functional theory studies on the dramatic activation mechanism. ACS Appl. Mater. Interfaces 2018, 10, 32567-32578) Reference [113]. Copyright (2020) American Chemical Society. 
The molybdenous modification improved the Michaelis-Menten parameters of lamellar $\mathrm{Co}(\mathrm{OH})_{2}$. Exfoliated $\mathrm{MoSe}_{2}$ sheets with few hundreds nm lateral size also possessed superb peroxidase mimicking properties [114]. Although this structure's maximum rate in $\mathrm{H}_{2} \mathrm{O}_{2}$ decomposition with TMB as chromogen is lower than that of native HRP's, the $\mathrm{K}_{\mathrm{m}}$ values observed are outstanding, making the material an effective sensor for xanthine and $\mathrm{H}_{2} \mathrm{O}_{2}$ detection (Table 1).

Huang et al. proved that $\mathrm{VS}_{2}$ sheets catalyzes homolytic cleavage of $\mathrm{H}_{2} \mathrm{O}_{2}$ in a faster reaction than HRP and the nanozyme also possesses higher affinity to both $\mathrm{H}_{2} \mathrm{O}_{2}$ and TMB compared to the native enzyme [115]. The same mechanism was implied for a BN@CuS composite [116], suitable for detection of cholesterol and for an HRP@WS ${ }_{2}$ hybrid [150], evidently. Several different sulfides were used as a composite building block with montmorillonites, which are detailed later.

\section{Metal Organic Frameworks (MOFs)}

MOFs are a subgroup of coordination polymers built up by metal ions coordinated and interlinked by multidentate bridging organic ligands [48]. In MOFs, the coordination network contains voids leading to enlarged surface area. Utilizing their favorable surface properties, Huang et al. constructed ca. $4 \mathrm{~nm}$ thick $\mathrm{Cu}$-based MOFs with Fe or Co complexes of a porphyrin ligand (tetrakis(4-carboxyphenyl)porphyrin, TCPP) decorated with $2 \mathrm{~nm}$ spherical Au NPs [151]. While the bare MOF was attested to be a peroxidase mimic (in acidic buffers near $\mathrm{pH} 3-4$, similar for all MOFs with peroxidase activity), Au deposition turned the material into a GOx mimic, after which the concentration of gluconic acid was measured by a photometric assay. Similarly, Qin et al. used the same Fe-TCPP in $\mathrm{Zn}$, Co and Cu-MOFs as peroxidases with altered activity in the presence of numerous phosphates of biological relevance [152]. Based on their activity change, the peroxidase probe reaction was utilized to detect the biomolecules mixed with the MOFs. Ultrathin $(2 \mathrm{~nm})$ variants of the same $\mathrm{Cu}$ and $\mathrm{Co}-\mathrm{MOF}$, alongside a Ni-containing one, were also synthesized and used as a modifier on glassy carbon electrodes fused with carbon nanotubes or graphene oxide [49].

Although MOFs are noteworthy peroxidase nanozymes under $\mathrm{pH} 5$, this value makes it hard for researchers to utilize them during in vivo experiments. Bridging this gap, a cascade system was fabricated using the well-known Cu-MOF applying Fe-TCPP in the synthesis [153]. In the first step, GOx was immobilized on the framework that oxidized glucose in the presence of molecular $\mathrm{O}_{2}$. During this reaction, the $\mathrm{pH}$ dropped (Figure 8), therefore the generated $\mathrm{H}_{2} \mathrm{O}_{2}$ was decomposed by a self-activated peroxidase mechanism. The resulting $\mathrm{OH}$. radicals are strong potent antibacterial agents, decimating S. aureus bacteria after injecting onto mice wound using a band-aid containing the biocompatible GOx@MOF and glucose. 


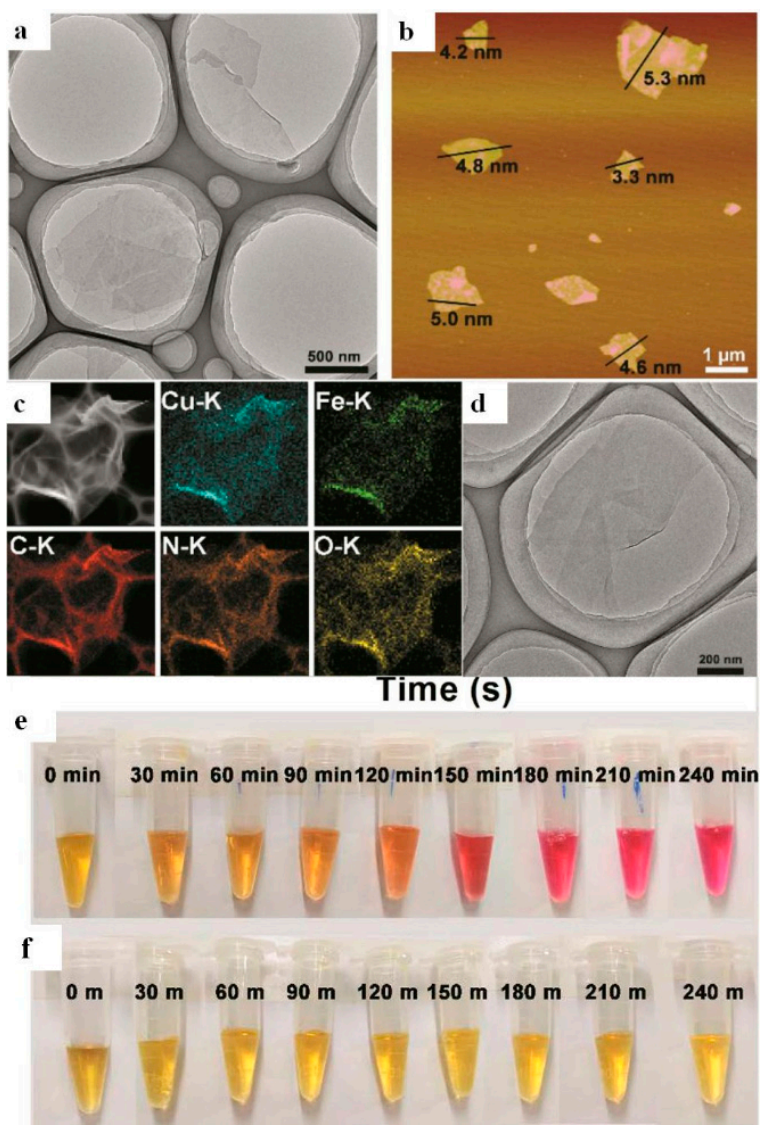

Figure 8. TEM micrograph of $\mathrm{Cu}-\mathrm{TCPP}(\mathrm{Fe}) 2 \mathrm{D}$ MOF nanosheets (a). AFM image of $\mathrm{Cu}-\mathrm{TCPP}(\mathrm{Fe}) 2 \mathrm{D}$ MOF nanosheets and their thickness distribution (b). Darkfield TEM image of typical Cu-TCPP(Fe) 2D MOF nanosheets and the corresponding TEM element mappings (c). TEM image of Cu-TCPP(Fe) 2D MOF/GOx (d). Time-dependent color changes of TMB reaction solutions catalyzed by the $\mathrm{Cu}-\mathrm{TCPP}(\mathrm{Fe})$ 2D MOF/GOx every $30 \mathrm{~min}$ in pH 7.4 PBS buffer (0-240 min, e) or pH 7.4 PBS buffer (0-240 m, f). Methyl red $\mathrm{pH}$ indicator $(0.001 \%)$ was used to signal the developing acidic conditions. Reprinted with permission from (Liu, X.P.; Yan, Z.Q.; Zhang, Y.; Liu, Z.W.; Sun, Y.H.; Ren, J.S.; Qu, X.G. Two-dimensional metal-organic framework/enzyme hybrid nanocatalyst as a benign and $\mathrm{m}$ self-activated cascade reagent for in vivo wound healing. ACS Nano 2019, 13, 5222-5230) Reference [153]. Copyright (2020) American Chemical Society.

Chen et al. obtained Ni-MOF with $p$-benzenedicarboxylate ligands [117]. In acidic acetate buffer, TMB was oxidized via the peroxidase intrinsic activity of the material. The nanosheets had impeccable affinity towards the substrates, while maintaining high maximum rate. Since the selectivity of the catalyst was high, it was applied in the detection of $\mathrm{H}_{2} \mathrm{O}_{2}$ in human serum samples with good accuracy. Furthermore, the material possessed remarkably low limit of detection.

\section{Layered Double Hydroxides (LDHs)}

The main structural motifs of LDHs are the positively charged metallic lamellae containing metal ions coordinated by hydroxide ions [5]. Generally, they are based on divalent and trivalent cations, although many exceptions are known. Since the surplus layer charge is neutralized by interlamellar (or intercalated) anions, the family of LDHs is suitable for immobilization of enzymatic $[118,154]$ and molecular $[119,155,156]$ antioxidants. Alternatively, large antioxidants may be anchored to the outer surface of LDHs through electrostatic attraction [60]. In this section, LDHs modified with simpler, then more complex drugs via intercalation will be introduced first. Thereafter, surface modified LDHs of antioxidant effect will be discussed, followed by some details about LDH nanozymes. 
Among antioxidant drugs, the main target molecules for intercalation are phenolic compounds, e.g., ascorbic acid, ferulic acid and gallic acid. Gallate, the anionic form of gallic acid, preserved its antioxidant character in MgAl-LDH [119] and ZnAl-LDH [120]. Release kinetics were also scoped and for ZnAl-LDH, parabolic model (governed by intraparticle diffusion) provided the best fit, while for MgAl-LDH, a fast, diffusion-controlled stage (Freundlich model) was followed by the slow parabolic release. The antioxidant capacity was evaluated in DPPH assays. MgAl(gallate)-LDH scavenged 83.9\% of initial DPPH radicals and the same method yielded a maximal 95\% scavenging for $\mathrm{ZnAl}$ (gallate)-LDH. A plausible reason of the difference may arise from the synthetic procedure: the $\mathrm{ZnAl}$ variant was obtained from the delamination-reconstruction process, which can lead to LDHs of higher surface area, contrary to the coprecipitation method used for the synthesis of $\mathrm{MgAl}$ (gallate)-LDH.

Beside the gallate-containing MgAl-LDH, Kong et al. also crafted carnosine-intercalated MgAl-LDH through ion-exchange, which provided nearly complete scavenging (95.9\%) of DPPH radicals [119]. Interestingly, although gallic acid is a strong antioxidant [87,157], it can act as a prooxidant [157], especially without oxidants present. This effect was exploited by Arratia-Quijada et al., who prepared $\mathrm{ZnAl}$ (gallate)-LDH that was used as cytotoxic agent against lung cancer cells [158]. Lima et al. modified ZnAl-LDH with ferulate anions [159]. The intercalant is known for its high antioxidant effect as a pure substance, but the authors proved that ferulate keeps its advantageous scavenging properties in the LDH as well and thus, successfully preventing $\mathrm{H}_{2} \mathrm{O}_{2}$-induced oxidative damage generation in fibroblast cultures. The prolonged release $(10 \mathrm{~h})$ from the carrier meant that the protective effect could be maintained for longer time frames. Similar multi-hour release kinetics was measured for two of the most known antioxidant, ascorbic acid (from MgAl-, MgFe- [160] and CaAl-LDH host [161]) and epigallocatechin gallate (from CaAl-LDH [162]).

Recently, polyphenolic ellagic acid (EA) was used to prepare an antioxidant LDH hybrid. Although the cleavage of lactone bonds in EA occurred, the material preserved its antioxidant activity after intercalation. Additionally, the LDH shell served as a tool to drastically improve the dispersibility of the originally hydrophobic EA. It was also proved that the release of EA from the mixed material is minimal. Organic solvents were also used to modify the surface properties of the hybrids and the originally ca. $60 \%$ DPPH scavenging activity of untreated EA-LDH increased to ca. $90 \%$ after treatment with ethanol and acetonitrile [121]. The materials also showed high TEAC (trolox equivalent antioxidant capacity) values. Trolox is the common name of 6-hydroxy-2,5,7,8-tetramethylchroman-2-carboxylic acid.

Regarding larger, but still molecular antioxidants, the most common target molecules are polyphenols. In this family, BHPPA (3-(3, 5-di-tert-butyl-4-hydroxy-phenyl)-propionic acid) is a model compound with good antioxidant effect, expressed in DPPH assay after intercalation in various LDHs $[156,163,164]$. The DPPH scavenging capability of such LDHs ranged from ca. $50 \%$ to $70 \%$, which are comparable to the $60-70 \%$ effectivity of pure BHPPA, depending on the reaction conditions. Even though the values obtained are well below $100 \%$, the nanocomposites were excellent polypropylene (PP) stabilizers against accelerated oxidation (Figure 9) [163], which probably arose from i) the BHPPA-protective effect of the LDH structure and ii) the general polymer stabilizing characteristics of LDHs originated from endothermic water loss at higher temperatures [165] and the reduced gas permeability through plastic [166]. The BHPPA-LDH hybrid surpassed Irganox 1010 [164], a frequent polymer antioxidant used in the industry. 

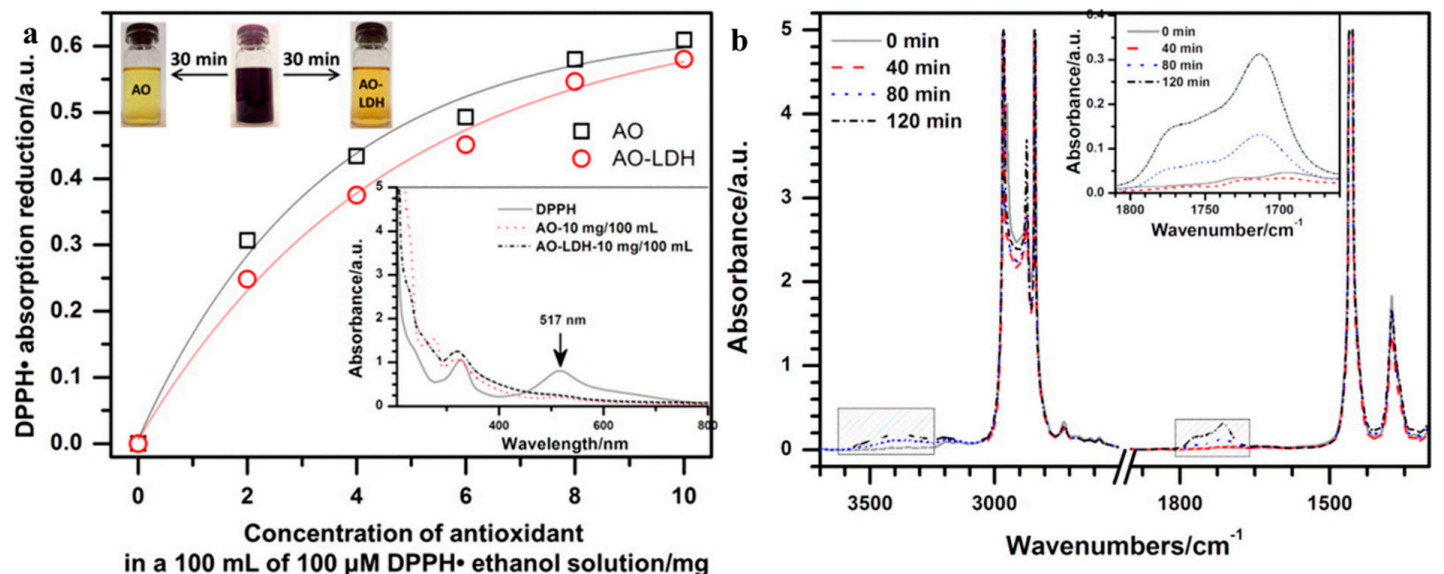

Figure 9. Radical-scavenging activity of BHPPA (denoted as AO) and BHPPA-LDH in a $100 \mathrm{~mL}$ of $100 \mu \mathrm{M}$ DPPH ethanolic solution. The top inset represents the color change and the bottom inset shows UV-Vis absorption curves after radical scavenging for $30 \mathrm{~min}$ in a dark box (a). FT-IR absorbance spectra of pure PP in the range of $3700-1250 \mathrm{~cm}^{-1}$ as a function of accelerated thermal aging time at $150{ }^{\circ} \mathrm{C}$. Inset shows a magnified region of the FT-IR spectra in the wavenumber range of $1810-1660 \mathrm{~cm}^{-1}$, thus the carbonyl region indicating oxidation of the plastic (b). Reprinted with permission from (Feng, Y.J.; Jiang, Y.; Huang, Q.; Chen, S.T.; Zhang, F.B.; Tang, P.G.; Li, D.Q. High antioxidative performance of layered double hydroxides/polypropylene composite with intercalation of low-molecular-weight phenolic antioxidant. Ind. Eng. Chem. Res. 2014, 53, 2287-2292) Reference [163]. Copyright (2020) American Chemical Society. BHPPA: (3-(3, 5-di-tert-butyl-4-hydroxy-phenyl)-propionic acid; LDH: layered double hydroxides

In 2013, Lonkar et al. also reported the improved thermal behavior of PP containing BHPPA-LDH as a filler [167]. Gomez Amaro et al. investigated BHPPA and Trolox in intercalated from [122], revealing up to $90 \%$ DPPH scavenging for both antioxidant-modified LDHs with 14 and 13 mass\% organic content, respectively. Irganox 1425, an ionic antioxidant consisting of a benzylphosphonate-type anion in $\mathrm{Ca}^{2+}$ salt, a common building block in the LDH structures, was used as precursors to prepare CaAl-LDH intercalated with its anion [155]. The polymer additive kept its DPPH scavenging activity after intercalation with ca. 55\% maximum effect, which is very similar, if not slightly higher than bare Irganox 1425. The LDH hybrid of olanzapine (2-methyl-4-(4-methylpiperazin-1-yl)-10H-thieno [2,3-b][1,5]-benzodiazepine) was also developed to overcompensate its low water solubility [123]. This drug molecule is a popular antipsychotic agent and due to the correlation between oxidative stress and brain damage [168], its antioxidant potential may be a reason for its pharmaceutical efficacy. It was demonstrated that the LDH hosts (CaAl- and NiAl-LDH) did not have negative effects in the assays investigated, e.g., DPPH assay, ABTS assay, NO scavenging and TBARS (TBA reactive substances) test. Moreover, the LDHs had synergistic effects with the olanzapine molecules. This was more pronounced for CaAl-LDH, which was often significantly more active than NiAl-LDH, as a carrier for olanzapine.

As mentioned earlier, larger, or more importantly, positively charged agents can be immobilized only via surface modifications. These examples tend to find enzymatic applications, e.g., the histamine (Hsm) containing $\mathrm{Cu}(\mathrm{Hsm})_{2}{ }^{2+}$ complex fixed on a polymer modified MgAl-LDH surface [124]. Poly(vinylpyridine-b-methacrylic acid (PVPMAA) copolymer of negative charge was used to reverse the originally positive surface charge of LDH enabling the adsorption of the positively charged $\mathrm{Cu}^{2+}$ complex. Charge reversal also achieved higher colloidal stability, i.e., the LDH precipitated at higher background electrolyte concentrations. The complex-LDH composite was then used as a SOD mimic with comparable activity to bare SOD or a SOD-coated MgAl-LDH [60]. The latter material was obtained by modifying the surface of SOD-MgAl-LDH composite by heparin (Hep) polyelectrolyte giving rise to highly stable antioxidant dispersions. It was apparent that both SOD functioning LDHs 
were highly active, but unlike natural enzymes, $\mathrm{Cu}(\mathrm{Hsm})_{2}{ }^{2+}$ was not heat sensitive and kept $90 \%$ of its activity at $80^{\circ} \mathrm{C}$, while SOD quickly denatured at higher temperatures (Figure 10).
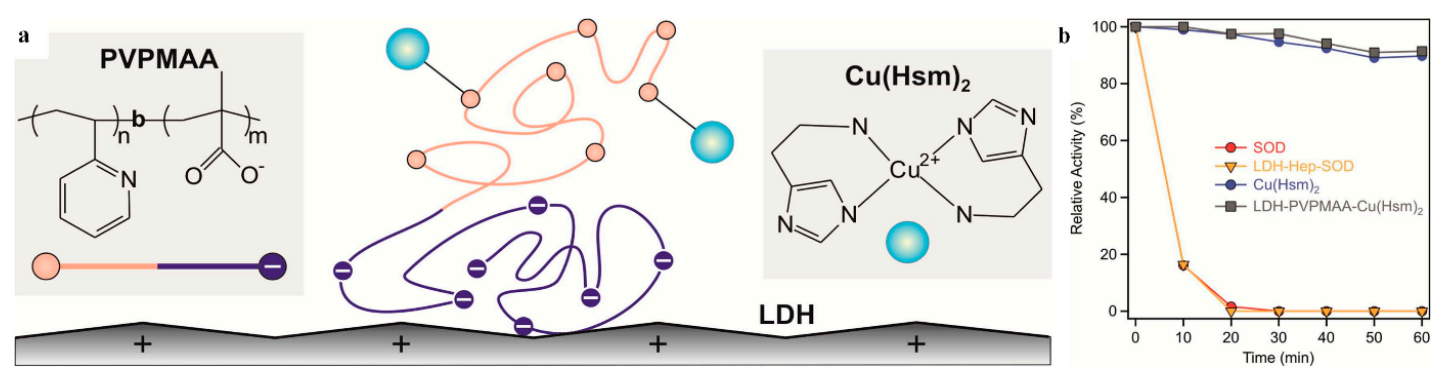

Figure 10. Schematic representation of formation of $\mathrm{Cu}(\mathrm{Hsm})_{2}{ }^{2+}$ on PVPMAA-coated LDH (a) and its activity in SOD assay compared to bare SOD, LDH-Hep-SOD and $\mathrm{Cu}(\mathrm{Hsm})_{2}{ }^{2+}$ at $80{ }^{\circ} \mathrm{C}$ as a function of reaction time (b). Reprinted from (Highly stable enzyme-mimicking nanocomposite of antioxidant activity, 543, Pavlovic, M.; Nafradi, M.; Rouster, P.; Murath, S.; Szilagyi, I., J. Colloid Interface Sci. 2019, 543, 174-182) Reference [124] Copyright (2020), with permission from Elsevier.

The intrinsic peroxidase activity was enhanced using deoxyribonucleic acid (DNA) from herring sperm [125]. The hybrids were constructed by surface electrostatic force between the building blocks. Furthermore, DNA-induced delamination of the carrier LDH (proved by X-ray powder diffraction and light scattering) facilitated the antioxidant reaction in the TMB test reaction, which showed best activity at $35-45^{\circ} \mathrm{C}$ and at $\mathrm{pH} 3-4$ with sudden decrease afterwards. Combined with GOx-glucose pair, Chen et al. used their DNA-LDH hybrid as a colorimetric glucose sensor.

Natural HRP bears gross positive charge in its active form, thus a Hep coating was used on the surface of MgAl-LDH before its immobilization [118]. The kinetic parameters in the guaiacol assay of the as-prepared composite LDH were slightly different compared to the free enzyme, representing that adsorption forces were insufficient to overcome the protein rigidity and to considerably influence the native structure of the enzyme. Beforehand, HRP-containing LDHs were synthesized using transition metal LDHs that were applied in the electrochemical detection of $\mathrm{H}_{2} \mathrm{O}_{2}[154,169]$.

Mimicking the active site of HRP, hemin was immobilized in/on FeNi- and CuAl-LDH by Zhang et al. [170] and Qiao et al. [171], respectively. Despite its size, hemin is a good target for intercalation owing to the planar structure and negative charge through the carboxylic groups. It was demonstrated that $\mathrm{FeNi}($ hemin)-LDH was an excellent peroxidase, surpassing free hemin. This is attributed to the dimerization of hemin outside the layered material, while in intercalated form, the hemin rings are mostly found as monomers. Finally, Zhang et al. developed an electrochemical sensor based on this material [170]. The CuAl(hemin)-LDH designed by Qiao et al. was tested as a scavenger of $\mathrm{ONOO}^{-}$ions [171] (Figure 11). They also found that the composite was more active than hemin alone, which is interpreted by the electrostatic attraction between the anionic $\mathrm{ONOO}^{-}$and the LDH particles, and also due to the $\pi$ donor property of LDHs to the Fe center of hemin, as stated by the authors. The composite also inhibited the reaction between tyrosine and $\mathrm{ONOO}^{-}$up to $80 \%$. 

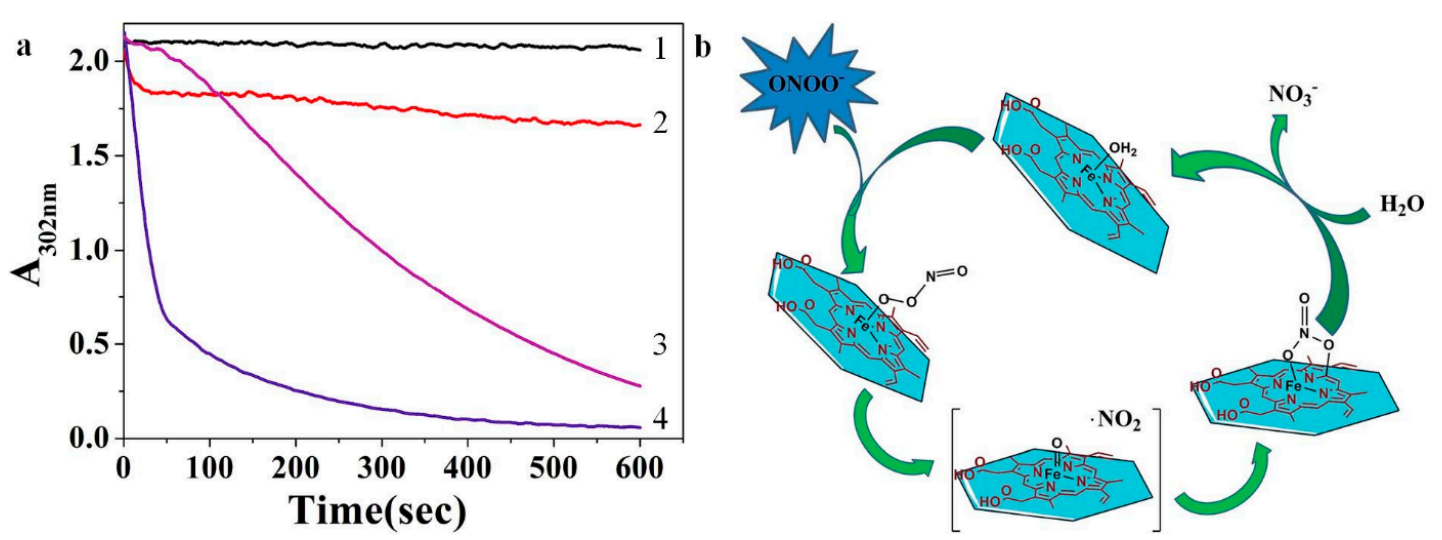

Figure 11. Peroxynitrite decomposition without (1) and with equivalent weight of LDHs (2), hemin (3) and hemin-LDHs (4). Peroxynitrite was mixed with scavengers at $25^{\circ} \mathrm{C}$ and the reaction was followed at $302 \mathrm{~nm}$ (a). Proposed mechanism for the isomerization and reduction of $\mathrm{ONOO}^{-}$and scavenging of $\mathrm{NO}_{2}$.by hemin-LDH hybrid nanosheets (b). Reproduced from Reference [171] with permission from the Royal Society of Chemistry.

A novel protein-LDH interaction was recently revealed when protein extracted from bael (Aegle marmelos) were anchored to the outer surface of MgAl-LDH [126]. The natural antioxidant proteins were scavengers of DPPH radicals on the LDHs (ca. 50\% effectivity) and possessed antimicrobial effect towards S. coliform. In addition, the composite adsorbed $\mathrm{Pb}^{2+}$ ions according to Freundlich model.

The earliest report on LDHs with intrinsic nanozyme activity was published by Zheng et al. [172]. For this purpose, like for all the others, redox active metal ions are represented in the lamellae. In this instance, $\mathrm{CoFe}-\mathrm{LDH}$ was used as a peroxidase mimic. The characteristics of the nanozyme were like those of $\mathrm{HRP}$, regarding optimal $\mathrm{pH}$ and temperature dependence, but the platelets were active in a larger $\mathrm{H}_{2} \mathrm{O}_{2}$ concentration regime. Thus, $\mathrm{H}_{2} \mathrm{O}_{2}$ detection is possible in a range of reaction conditions. The obtained LDH was also used in the GOx mediated selective sensing of glucose via TMB test reaction. Afterwards, CoAl-LDH sheets exfoliated in L-asparagine solution were proven to have peroxidase mimic with $\mathrm{pH}$ optimum at 6 [127]. A similar approach with L-asparagine was applied to get exfoliated 2D NiFe-LDH with $2 \mathrm{~nm}$ thickness [128]. Both asparagine exfoliated LDHs showed Tyndall effect in aqueous suspension, indicating the formation of stable colloids. While the nanosheets of CoAl-LDH showed relatively lower affinity to $\mathrm{H}_{2} \mathrm{O}_{2}\left(\mathrm{~K}_{\mathrm{m}}=22.1 \mathrm{mM}\right), \mathrm{NiFe}-\mathrm{LDH}$ and bare HRP had similar values with 2.4 and $3.7 \mathrm{mM}$, respectively (Table 1). The detection limit of NiFe-LDH was estimated to be $4.4 \mathrm{mM} \mathrm{H}_{2} \mathrm{O}_{2}$. The peroxidase-like activity of $\mathrm{NiCo}-\mathrm{LDH}$ was described by $\mathrm{Su}$ et al. using homovanillic acid as a fluorescent dye upon reacting with $\mathrm{H}_{2} \mathrm{O}_{2}$ [173]. It was found that the catalysis was strongly $\mathrm{pH}$ dependent and reached optimum above $\mathrm{pH} 8.3$ with a linear response at $\mathrm{pH}$ between 8.4 and 8.9, before plateauing at 9.6. Another peroxidase mimic, $\mathrm{CuAl}-\mathrm{LDH}$ was grown onto carbon fibers (Figure 12) after atomic layer deposition of $\mathrm{Al}_{2} \mathrm{O}_{3}$ and hydrothermal conversion to the end-product [174]. Interestingly, the optimum temperature for this material was $70{ }^{\circ} \mathrm{C}$, but at 60 and $80^{\circ} \mathrm{C}$, it showed similar efficiency. Activity also grew when using more catalyst, indicating that the reaction was not diffusion controlled. It was also shown that radical scavengers inhibit the catalytic reaction in a great manner. Peroxidase nanozyme CoFe-LDH was used as catalyst to obtain fluorescent polydopamine (PDA) from its monomer [175]. This procedure avoided using concentrated $\mathrm{H}_{2} \mathrm{O}_{2}$ and yielded shorter reaction times. PDA is strongly fluorescent in aqueous solutions which is quenched by $\mathrm{Fe}^{3+}$ ions through coordination. However, intensity is restored when strong iron complexing pyrophosphate is introduced, with good linearity and selectivity. Another detection is possible through the addition of pyrophosphatase, which decomplexes the quenching $\mathrm{Fe}^{3+}$ ions and lower fluorescent signal is observed. 

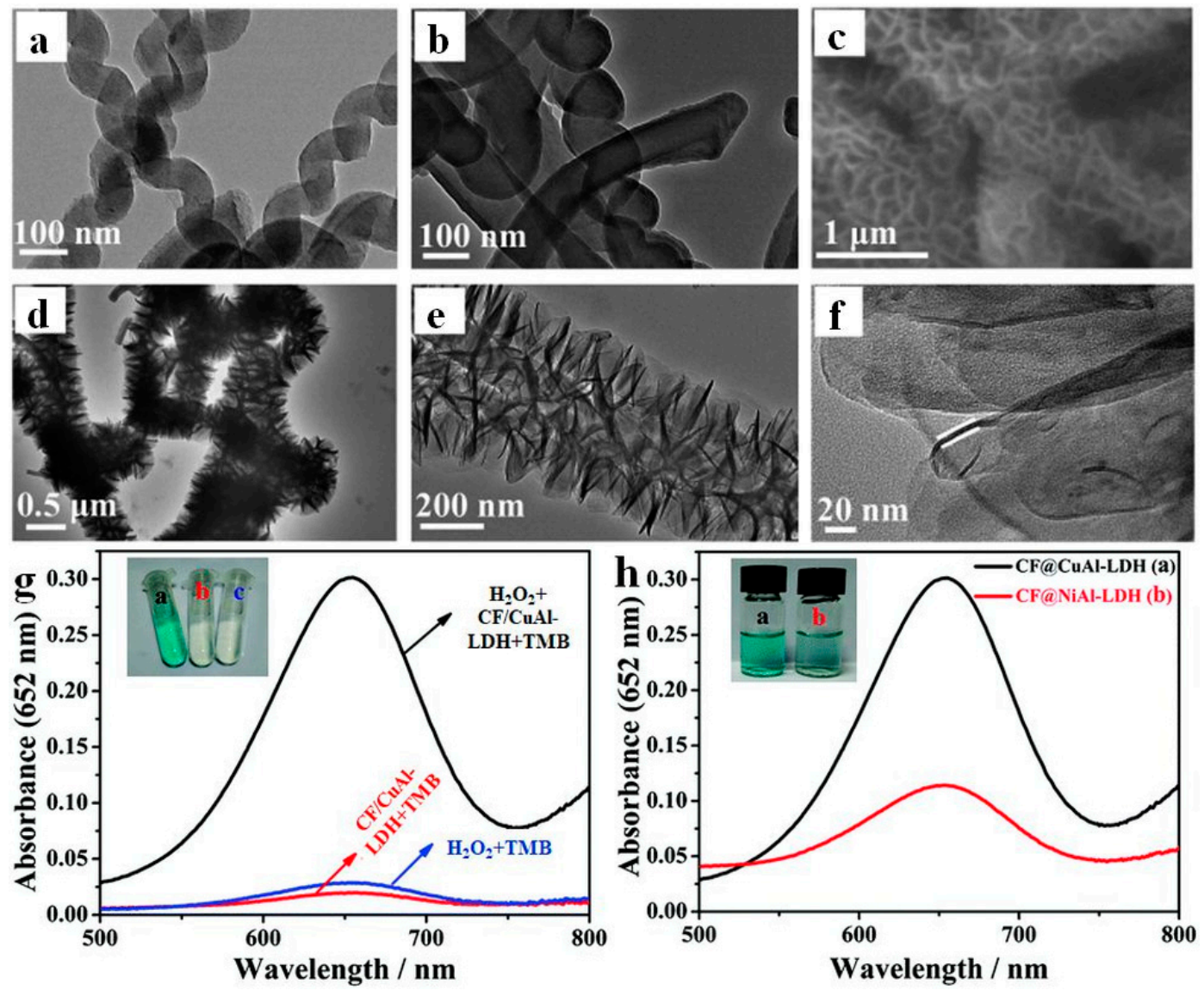

Figure 12. TEM micrograph of carbon fiber $(\mathrm{CF})(\mathbf{a})$ and $\mathrm{CF} / \mathrm{Al}_{2} \mathrm{O}_{3}(\mathbf{b})$. SEM micrograph of $\mathrm{CF} / \mathrm{CuAl}-\mathrm{LDH}$ (c). TEM and HRTEM images of CF/CuAl-LDH (d-f). Absorbance in different reaction systems (g) and in different types of LDHs (h). Reproduced from Reference [174] with permission from the Centre National de la Recherche Scientifique (CNRS) and the Royal Society of Chemistry.

Recently reported MnFe-LDH possessed catalase mimicking activity and exhibited photothermal effect [176]. Methylene blue loading enhanced the efficacy of $\mathrm{O}_{2}$-dependent photothermal phenomenon. This way, the phototherapic effect in hypoxia cancer cells were gapped, as demonstrated in human cells and mice, in which the relative size of tumor was also reduced. We mention that even though it was not used as an antioxidant, rather a prooxidant, but $\mathrm{Fe}^{2+}$ bearing FeAl-LDH was used to decompose $\mathrm{H}_{2} \mathrm{O}_{2}$ with a Fenton-type mechanism inducing apoptosis in cancer cells through the generated $\mathrm{OH}$. and $\mathrm{OOH}$. radicals [129].

\section{Montmorillonites (MMTs)}

Montmorillonites are sheet-like silicate minerals with anionic layers and feasible, water-exchangeable cations between the individual sheets $[31,130,177]$. Their charging features, therefore, are the reverse of the already discussed LDHs. Hence, MMTs may possess antioxidant capacity by their own through fixing antioxidant compounds in their structures (e.g., intercalation or physical adsorption) or by the preparation of composite materials with synergistic nanomaterials.

Regarding intercalated MMTs, Baek et al. constructed GSH-containing MMT, coated with poly(vinylacetal diethylaminoacetate) (AEA) [130]. GSH is the most common antioxidant material in the body, but with low bioavailability, in case it is taken in orally. Carriers can overcome this barrier and it was found that GSH and GSH-MMT had an ABTS radical scavenging activity of ca. $60 \%$. Diethyl aminoacetate coating was also introduced as a protective layer, which did not interfere with the antioxidant effect. After oral administration for mice, the concentration of GSH significantly 
grew in liver, to which delivery of free GSH is minimal. Naturally occurring ionic species may also be intercalated from plant extracts, e.g., antioxidants from blueberry (Vaccinium corymbosum) that provided an intelligent potential food packaging nanomaterial, which is color-sensitive to $\mathrm{pH}$ [131]. Compared to the negligible DPPH scavenging activity of pure MMT (which probably arose from adsorption), the blueberry extract-modified clay showed exceptional activity with ca. $40 \%$ scavenging.

An antioxidant activity, close to the one of ascorbic acid, was assigned to the eugenol-MMT hybrid that was used as a filler in poly(3-hydroxybutyrate)-thermoplastic (PHB-TPS) starch composite that resulted in a functional material with evolved heat resistance and mechanical properties that also possessed antioxidant and antifungal properties [132]. The peroxidase nanozyme activity of hemin was demonstrated after adsorbing its highly active monomeric form in $7 \mathrm{mg} / \mathrm{g}$ dose on MMT [133]. Earlier, it was demonstrated that histidine amino acid residues activate the catalytic activity of HRP [178], which was substituted with intercalated Hsm in the case of hemin-MTT. This way, the relative catalytic activity of the MMT composite jumped to over $350 \%$ at $60{ }^{\circ} \mathrm{C}$, where the performance of natural HRP decreased.

A chitosan (CS) coated MMT@(Ca-alginate) nanoparticle synthesis was recently reported with covalently bonded HRP enzyme on its outer surface to degrade aflatoxin B1 [179], a dangerous poison produced by molds. The role of negatively charged MMT in this structure was to promote aflatoxin adsorption and to attract more chitosan chains. Multiple chitosan/MMT composites were prepared in Fernando's group as a biocompatible substitute of classic polymer food wrappers $[177,180,181]$. These materials had adequate physical characteristics (tensile strength, optical properties, etc.) and were incorporated with rosemary (Rosmarinus officinalis) and ginger (Zingiber officinale) essential oils. This incorporation provided the composite with good antimicrobial activity and antioxidative protection for applications in poultry packaging. Yan et al. used $\alpha$-tocopherol (TOC) in a chitosan-MMT matrix as preservative for wrapping sliced ham with film of the material [134]. The film coating showed good antioxidant activity in DPPH assay even after 16-day storage, while in lipid oxidation tests, the remarkable antioxidant effect was expressed after 120 days.

Regarding MMT composites with other inorganic materials of overall antioxidant capacity, sulfide-MMT structures were under investigation previously. A facile way was worked out to construct ZnS/MMT composite via coprecipitation [135]. This material acted as a peroxidase mimic in a rapid fashion with merely a few minutes to form oxidized TMB. The activity measured was similar in the $\mathrm{pH}$ range $4-7$ and from 20 to $70{ }^{\circ} \mathrm{C}$. Besides, outstanding substrate affinity was achieved, compared to bare HRP (148-fold and 8-fold increase towards $\mathrm{H}_{2} \mathrm{O}_{2}$ and TMB, respectively). A CuS/MMT composite was also considered as a peroxidase mimic with short timeframe $(<1 \mathrm{~min})$ to reach colorimetric visualization with poorer kinetic parameters [136] (Table 1). Reaction kinetics for ZnS/MMT were also proved by EPR, trapping and detecting the $\mathrm{OH}$. radicals formed from $\mathrm{H}_{2} \mathrm{O}_{2}$ by DMPO spin trap. A very similar coprecipitation method, starting from thioacetamide, was used to obtain $\mathrm{Ag}_{2} \mathrm{~S} / \mathrm{MMT}$ composite [137]. The $\mathrm{pH}$ and temperature dependence profiles were fairly similar to other MMT systems and it was found that pure MMT also possessed peroxidase activity. In this case, terephtalic acid was used as fluorescent $\mathrm{OH}$. radical trap to confirm the mechanism. Recently, the composite of MMT and $\mathrm{CoNiS}_{\mathrm{x}}$ was prepared, and remarkable peroxidase activity was observed [138]. It exhibited good affinity towards $\mathrm{H}_{2} \mathrm{O}_{2}$ and TMB substrates, often surpassing bare HRP. Contrary to other MMT composites, elevated temperatures had negative impact on its activity above $35^{\circ} \mathrm{C}$, but at ambient temperatures showed linear response to $\mathrm{H}_{2} \mathrm{O}_{2}$.

MMT was also found to be the ideal clay mineral for soil organic matter modification linked with HRP adsorption [139]. Furthermore, MMT retained 91.3\% activity of bare HRP and was reusable for phenol removal, tested for six cycles with slight activity loss.

Heterobinuclear [140] and mononuclear [141] $\mathrm{Cu}^{2+}$ complexes containing amine and amino acid ligands were intercalated between the layers of MMT to obtain a heterogeneous catalysts for dismutation of superoxide radicals. The composites showed significant SOD-like function in the test reactions, in which the superoxide radical anions were generated by a photochemical reaction. 
Finally, montmorillonite-intercalated $\mathrm{Cu}^{2+}$-tris(2-aminoethyl) amine complexes were highly active in decomposition of $\mathrm{H}_{2} \mathrm{O}_{2}$, i.e., they acted as an excellent catalase mimicking antioxidant composite [182].

\section{Miscellaneous Structures}

Structures listed in this paragraph either did not fall under the categories listed before or were borderline (e.g., $\mathrm{CeO}_{2} @ \mathrm{CO}_{2}(\mathrm{OH})_{2} \mathrm{CO}_{3}$ ) or were the only example of the material (see $\mathrm{Fe}_{2} \mathrm{O}_{3}$ ).

He et al. published the synthesis of flaky CoP 2D particles on Ni foam substrate [142]. First, $\mathrm{Co}(\mathrm{OH})_{2}$ was built on the metal carrier, which was phosphorylated with $\mathrm{NaH}_{2} \mathrm{PO}_{2}$ in a hydrothermal manner. The precursor $\mathrm{Co}(\mathrm{OH})_{2}$ had mediocre activity in the peroxidase test reaction, the end product possessed outstanding performance, while Ni foam (NF) was completely inert. More importantly, the same piece of catalyst showed the same activity for 12 cycles, which was unaffected by $\mathrm{pH}(2-14)$ and temperature $\left(0-95^{\circ} \mathrm{C}\right)$. The material was successfully used to detect uric acid in serum samples (with overall $5 \%$ error compared to clinical method) and in real urine samples as well with good selectivity to the substrate (Figure 13).

$\mathbf{a}$

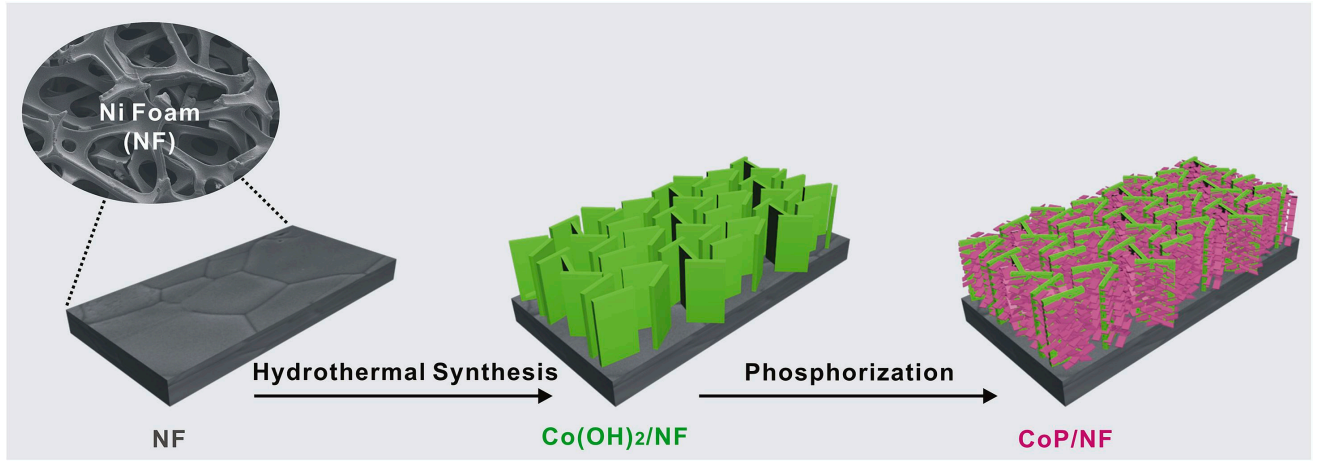

b

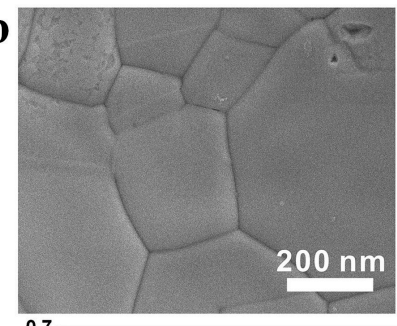

c
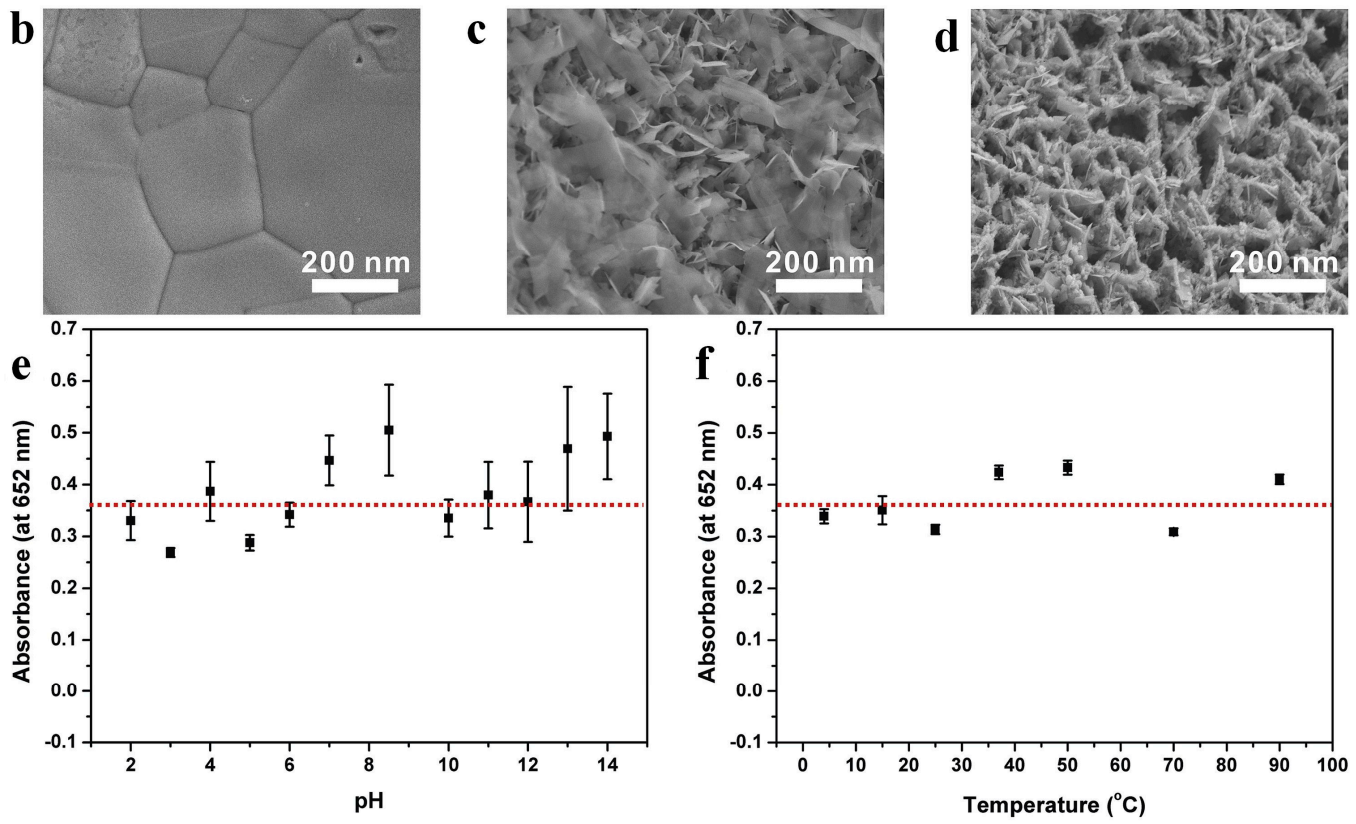

Figure 13. Illustration of the fabrication procedure of $\mathrm{CoP} / \mathrm{NF}(\mathbf{a})$; $\mathrm{SEM}$ micrographs of NF (b); $\mathrm{Co}(\mathrm{OH})_{2} / \mathrm{NF}$ (c) and $\mathrm{CoP} / \mathrm{NF}(\mathbf{d})$; the robustness and versatility of the CoP/NF nanozyme against harsh pH (e) and temperature (f). Reprinted from (Uricase-free on-demand colorimetric biosensing of uric acid enabled by integrated $\mathrm{CoP}$ nanosheet arrays as a monolithic peroxidase mimic. 1021, He, Y. F.; Qi, F.; Niu, X. H.; Zhang, W. C.; Zhang, X. F.; Pan, J. M., Anal. Chim. Acta 2018, 1021, 113-120) Reference [142]. Copyright (2020), with permission from Elsevier. 
A facile detection method based on $\mathrm{CeO}_{2}$ nanoparticles on $2 \mathrm{D} \mathrm{CO}_{2}(\mathrm{OH})_{2} \mathrm{CO}_{3}$ was introduced by Alizadeh et al [143]. After the material was characterized as an excellent peroxidase mimic with higher maximum rate than HRP's, a paper based colorimetric immunoassay method was developed with smartphone image analysis selective to carcinoembryonic antigen.

Deshapriya et al. used aminated and artificially cationized BSA (bovine serum albumin) as an overcharging agent on negatively charged, exfoliated $\mathrm{ZrP}$ (standing for $-\mathrm{Zr}\left(\mathrm{HPO}_{4}\right)_{2}$ ) sheets [183]. This led to the possible immobilization of numerous enzymes, including catalase. For GOx and tyrosinase, loading up to 640 and 380 mass \% was achieved, respectively. Moreover, the bound enzymes kept their native structure and at least $80 \%$ of their activity, excluding tyrosinase with a value of ca. $40 \%$.

Iron containing simple compounds were also tested as peroxidases. $\mathrm{Fe}_{3}\left(\mathrm{PO}_{4}\right)_{2} \times 8 \mathrm{H}_{2} \mathrm{O}$ sheets in a flower-like array were utilized as a potent nanozyme to detect $\mathrm{H}_{2} \mathrm{O}_{2}$ with over 30 ionic and non-ionic abundant substances tested as an interfering agent, but the detection was considerably not distorted [144]. Glucose sensing was also achieved through the glucose-GOx reaction with good selectivity amongst other bioactive compounds. Tanaka et al. started from $\mathrm{Fe}^{3+}$-glycerate precursor and applied thermal treatment to obtain porous $\mathrm{Fe}_{2} \mathrm{O}_{3}$ flakes [145]. It was found that lower pyrolysis temperatures resulted in better Fenton-type activity for the synthesized $\mathrm{Fe}_{2} \mathrm{O}_{3}$, since those products had higher surface area and higher hexagonal $\alpha-\mathrm{Fe}_{2} \mathrm{O}_{3}$ content with more active sites compared to cubic $\gamma-\mathrm{Fe}_{2} \mathrm{O}_{3}$ (Table 1).

\section{Summary and Outlook}

As discussed above, antioxidant compounds of 2D structure has attracted widespread contemporary interest in the scientific and technological communities, wherever the goal is to decrease oxidative stress or to develop ROS sensing devices. The main advantages of the 2D structures are the high specific surface area and that processable samples for homogeneous film formation (e.g., for electrode modifications) can be easily prepared. Given the fact that these compounds are excellent candidates as building blocks of sensing materials, the ease of synthesis even in larger amount will definitely help in the commercialization of sensors and detectors.

Enzyme-loaded 2D NPs represent a very efficient ROS consuming class, however, the high sensitivity of the proteins to the environmental conditions often remains upon immobilization. Such a low resistance against $\mathrm{pH}$, pressure and temperature can be improved by applying enzyme mimicking metal complexes as catalytic center in the 2D NP-based hybrids, but their efficiencies usually lag behind the one of the native enzymes. A returning problem in case of many molecular antioxidants is their low water solubility and thus, low bioavailability. The insufficient solubility may be increased by loading the 2D particles of high specific surface area with the antioxidant molecules, provided the carrier can be dispersed in liquid media. The new wave in the field of $2 \mathrm{D}$ antioxidants are the so-called nanozymes, which are able to decompose ROS without embedding enzymatic or molecular antioxidants in their structure. Metal-containing compounds hold great promise towards development of such 2D nanozymes.

Apart from the 2D antioxidant materials reported to date, novel hybrid materials are continuously being developed in the academic and industrial laboratories. Achieving excellent radical scavenging activity is the main priority, however, other important issues must also be considered. These include the physiological effect on living organisms, i.e., cell toxicity assessment is a must prior to the biomedical application. In addition, dispersions of antioxidant 2D particles are applied in most of the systems, therefore, the stability of the dispersions has to be precisely controlled. Unwanted particle aggregation processes lead to significant loss in the antioxidant activity and to non-processable samples. The stability issue can be solved by choosing appropriate stabilizing agents. Comprehensive studies in this topic are missing in the relevant literature.

Author Contributions: All authors participated in the manuscript preparation. All authors have read and agreed to the published version of the manuscript. 
Funding: Financial support by the Hungarian Academy of Sciences (Lendület 96130), the National Research, Development and Innovation Office (SNN_131558) and the Ministry of Human Capacities of Hungary (20391-3/2018/FEKUSTRAT) is gratefully acknowledged.

Conflicts of Interest: The authors declare no conflict of interest.

\section{References}

1. Sasikala, S.P.; Lim, J.; Kim, I.H.; Jung, H.J.; Yun, T.; Han, T.H.; Kim, S.O. Graphene oxide liquid crystals: A frontier 2D soft material for graphene-based functional materials. Chem. Soc. Rev. 2018, 47, 6013-6045. [CrossRef]

2. Anasori, B.; Lukatskaya, M.R.; Gogotsi, Y. 2D metal carbides and nitrides (MXenes) for energy storage. Nat. Rev. Mater. 2017, 2, 16098. [CrossRef]

3. Yu, J.F.; Wang, Q.; O'Hare, D.; Sun, L.Y. Preparation of two dimensional layered double hydroxide nanosheets and their applications. Chem. Soc. Rev. 2017, 46, 5950-5974. [CrossRef] [PubMed]

4. Wang, L.Z.; Sasaki, T. Titanium oxide nanosheets: Graphene analogues with versatile functionalities. Chem. Rev. 2014, 114, 9455-9486. [CrossRef] [PubMed]

5. Gu, Z.; Atherton, J.J.; Xu, Z.P. Hierarchical layered double hydroxide nanocomposites: Structure, synthesis and applications. Chem. Commun. 2015, 51, 3024-3036. [CrossRef]

6. Rahman, M.Z.; Kwong, C.W.; Davey, K.; Qiao, S.Z. 2D phosphorene as a water splitting photocatalyst: Fundamentals to applications. Energy Environ. Sci. 2016, 9, 709-728. [CrossRef]

7. She, X.J.; Wu, J.J.; Xu, H.; Zhong, J.; Wang, Y.; Song, Y.H.; Nie, K.Q.; Liu, Y.; Yang, Y.C.; Rodrigues, M.T.F.; et al. High efficiency photocatalytic water splitting using $2 \mathrm{D}$ alpha- $\mathrm{Fe}_{2} \mathrm{O}_{3} / g-\mathrm{C}_{3} \mathrm{~N}_{4}$ Z-scheme catalysts. Adv. Energy Mater. 2017, 7, 1700025. [CrossRef]

8. Gao, G.P.; O'Mullane, A.P.; Du, A.J. 2D MXenes: A new family of promising catalysts for the hydrogen evolution reaction. ACS Catal. 2017, 7, 494-500. [CrossRef]

9. Zhu, M.S.; Sun, Z.C.; Fujitsuka, M.; Majima, T. Z-scheme photocatalytic water splitting on a 2D heterostructure of black phosphorus/bismuth vanadate using visible light. Angew. Chem. Int. Ed. 2018, 57, 2160-2164. [CrossRef]

10. Jiang, X.; Wang, P.; Zhao, J.J. 2D covalent triazine framework: A new class of organic photocatalyst for water splitting. J. Mater. Chem. A 2015, 3, 7750-7758. [CrossRef]

11. Li, Y.G.; Li, Y.L.; Sa, B.S.; Ahuja, R. Review of two-dimensional materials for photocatalytic water splitting from a theoretical perspective. Catal. Sci. Technol. 2017, 7, 545-559. [CrossRef]

12. Yang, L.; Guo, Z.L.; Huang, J.; Xi, Y.N.; Gao, R.J.; Su, G.; Wang, W.; Cao, L.X.; Dong, B.H. Vertical growth of 2D amorphous FePO4 nanosheet on $\mathrm{Ni}$ foam: Outer and inner structural design for superior water splitting. Adv. Mater. 2017, 29, 1704574. [CrossRef] [PubMed]

13. Ida, S.; Ishihara, T. Recent progress in two-dimensional oxide photocatalysts for water splitting. J. Phys. Chem. Lett. 2014, 5, 2533-2542. [CrossRef] [PubMed]

14. Chen, B.; Zhang, Z.; Kim, S.; Baek, M.; Kim, D.; Yong, K. A biomimetic nanoleaf electrocatalyst for robust oxygen evolution reaction. Appl. Catal. B Environ. 2019, 259, 118017. [CrossRef]

15. Hussain, N.; Yang, W.J.; Dou, J.M.; Chen, Y.N.; Qian, Y.T.; Xu, L.Q. Ultrathin mesoporous F-doped -Ni(OH)(2) nanosheets as an efficient electrode material for water splitting and supercapacitors. J. Mater. Chem. A 2019, 7, 9656-9664. [CrossRef]

16. Sipiczki, M.; Adam, A.A.; Anitics, T.; Csendes, Z.; Peintler, G.; Kukovecz, A.; Konya, Z.; Sipos, P.; Palinko, I. The catalytic epoxidation of 2-cyclohexen-1-one over uncalcined layered double hydroxides using various solvents. Catal. Today 2015, 241, 231-236. [CrossRef]

17. Wang, X.R.; Han, X.; Zhang, J.; Wu, X.W.; Liu, Y.; Cui, Y. Homochiral 2D porous covalent organic frameworks for heterogeneous asymmetric catalysis. J. Am. Chem. Soc. 2016, 138, 12332-12335. [CrossRef]

18. Cao, L.Y.; Lin, Z.K.; Peng, F.; Wang, W.W.; Huang, R.Y.; Wang, C.; Yan, J.W.; Liang, J.; Zhang, Z.M.; Zhang, T.; et al. Self-supporting metal-organic layers as single-site solid catalysts. Angew. Chem. Int. Ed. 2016, 55, 4962-4966. [CrossRef]

19. Li, Y.Z.; Shu, J.; Huang, Q.Q.; Chiranjeevulu, K.; Kumar, P.N.; Wang, G.E.; Deng, W.H.; Tang, D.P.; Xu, G. 2D metal chalcogenides with surfaces fully covered with an organic "promoter" for high-performance biomimetic catalysis. Chem. Commun. 2019, 55, 10444-10447. [CrossRef] 
20. Xiao, Y.W.; Guo, W.X.; Chen, H.H.; Li, H.F.; Xu, X.J.; Wu, P.; Shen, Y.; Zheng, B.; Huo, F.W.; Wei, W.D. Ultrathin 2D Cu-porphyrin MOF nanosheets as a heterogeneous catalyst for styrene oxidation. Mater. Chem. Front. 2019, 3, 1580-1585. [CrossRef]

21. Reyna-Villanueva, L.R.; Dias, J.M.; Medellin-Castillo, N.A.; Ocampo-Perez, R.; Martinez-Rosales, J.M.; Penaflor-Galindo, T.; Fuentes, G.A. Biodiesel production using layered double hidroxides and derived mixed oxides: The role of the synthesis conditions and the catalysts properties on biodiesel conversion. Fuel 2019, 251, 285-292. [CrossRef]

22. Mei, X.; Xu, S.M.; Hu, T.Y.; Peng, L.Q.; Gao, R.; Liang, R.Z.; Wei, M.; Evans, D.; Duan, X. Layered double hydroxide monolayers for controlled loading and targeted delivery of anticancer drugs. Nano Res. 2018, 11, 195-205. [CrossRef]

23. Li, X.Q.; Gong, P.W.; Li, Y.Z.; Yu, J.F.; Wang, F.; Li, X.A.; Fan, Z.J.; Wang, Z.F. Double-carrier drug delivery system based on polyurethane-polyvinyl alcohol/layered double hydroxide nanocomposite hydrogel. Mater. Lett. 2019, 243, 1-4. [CrossRef]

24. Li, Q.L.; Wang, J.P.; Liu, W.C.; Zhuang, X.Y.; Liu, J.Q.; Fan, G.L.; Li, B.H.; Lin, W.N.; Man, J.H. A new $(4,8)$-connected topological MOF as potential drug delivery. Inorg. Chem. Commun. 2015, 55, 8-10. [CrossRef]

25. Sun, X.M.; Liu, Z.; Welsher, K.; Robinson, J.T.; Goodwin, A.; Zaric, S.; Dai, H.J. Nano-graphene oxide for cellular imaging and drug delivery. Nano Res. 2008, 1, 203-212. [CrossRef]

26. An, J.Y.; Geib, S.J.; Rosi, N.L. Cation-triggered drug release from a porous zinc-adeninate metal-organic framework. J. Am. Chem. Soc. 2009, 131, 8376-8377. [CrossRef] [PubMed]

27. Reddy, A.B.; Manjula, B.; Jayaramudu, T.; Sadiku, E.R.; Babu, P.A.; Selvam, S.P. 5-Fluorouracil Loaded Chitosan-PVA/Na ${ }^{+} \mathrm{MMT}$ Nanocomposite Films for Drug Release and Antimicrobial Activity. Nano Micro Lett. 2016, 8, 260-269. [CrossRef]

28. Yang, J.H.; Lee, J.H.; Ryu, H.J.; Elzatahry, A.A.; Alothman, Z.A.; Choy, J.H. Drug-clay nanohybrids as sustained delivery systems. Appl. Clay Sci. 2016, 130, 20-32. [CrossRef]

29. Garcia-Villen, F.; Faccendini, A.; Aguzzi, C.; Cerezo, P.; Bonferoni, M.C.; Rossi, S.; Grisoli, P.; Ruggeri, M.; Ferrari, F.; Sandri, G.; et al. Montmorillonite-norfloxacin nanocomposite intended for healing of infected wounds. Int. J. Nanomed. 2019, 14, 5051-5060. [CrossRef]

30. Cui, Z.K.; Kim, S.; Baljon, J.J.; Wu, B.M.; Aghaloo, T.; Lee, M. Microporous methacrylated glycol chitosan-montmorillonite nanocomposite hydrogel for bone tissue engineering. Nat. Commun. 2019, 10, 3523. [CrossRef]

31. Dong, Y.C.; Feng, S.S. Poly(D,L-lactide-co-glycolide)/montmorillonite nanoparticles for oral delivery of anticancer drugs. Biomaterials 2005, 26, 6068-6076. [CrossRef] [PubMed]

32. Kou, L.Z.; Frauenheim, T.; Chen, C.F. Phosphorene as a Superior Gas Sensor: Selective Adsorption and Distinct I-V Response. J. Phys. Chem. Lett. 2014, 5, 2675-2681. [CrossRef] [PubMed]

33. Campbell, M.G.; Liu, S.F.; Swager, T.M.; Dinca, M. Chemiresistive Sensor Arrays from Conductive 2D Metal-Organic Frameworks. J. Am. Chem. Soc. 2015, 137, 13780-13783. [CrossRef] [PubMed]

34. Late, D.J.; Doneux, T.; Bougouma, M. Single-layer $\mathrm{MoSe}_{2}$ based $\mathrm{NH}_{3}$ gas sensor. Appl. Phys. Lett. 2014, 105, 233103. [CrossRef]

35. Yang, S.X.; Jiang, C.B.; Wei, S.H. Gas sensing in 2D materials. Appl. Phys. Rev. 2017, 4, 021304. [CrossRef]

36. Wang, G.Y.; Yang, L.L.; Li, Y.; Song, H.; Ruan, W.J.; Chang, Z.; Bu, X.H. A luminescent 2D coordination polymer for selective sensing of nitrobenzene. Dalton Trans. 2013, 42, 12865-12868. [CrossRef]

37. Huang, Y.X.; Guo, J.H.; Kang, Y.J.; Ai, Y.; Li, C.M. Two dimensional atomically thin $\mathrm{MoS}_{2}$ nanosheets and their sensing applications. Nanoscale 2015, 7, 19358-19376. [CrossRef]

38. Xu, J.; Yan, D.P.; Li, S.D.; Lu, J. Controllable luminescence and electrochemical detection of $\mathrm{Pb}^{2+}$ ion based on the 2,2'-Azino-bis(3-ethylbenzothiazoline-6-sulfonate) dye and dodecanesulfonate co-intercalated layered double hydroxide. Dyes Pigment. 2012, 94, 74-80. [CrossRef]

39. Nandu, N.; Hizir, M.S.; Roberston, N.M.; Ozturk, B.; Yigit, M.V. Masking the peroxidase-like activity of the molybdenum disulfide nanozyme enables label-free lipase detection. ChemBioChem 2019, 20, 1861-1867. [CrossRef]

40. Liao, H.P.; Wang, H.M.; Ding, H.M.; Meng, X.S.; Xu, H.; Wang, B.S.; Ai, X.P.; Wang, C. A 2D porous porphyrin-based covalent organic framework for sulfur storage in lithium sulfur batteries. J. Mater. Chem. A 2016, 4, 7416-7421. [CrossRef] 
41. Hu, H.W.; Xin, J.H.; Hu, H.; Wang, X.W.; Miao, D.G.; Liu, Y. Synthesis and stabilization of metal nanocatalysts for reduction reactions-A review. J. Mater. Chem. A 2015, 3, 11157-11182. [CrossRef]

42. Rehman, J.; Fan, X.F.; Zheng, W.T. Computational insight of monolayer $\mathrm{SnS}_{2}$ as anode material for potassium ion batteries. Appl. Surf. Sci. 2019, 496, 143625. [CrossRef]

43. Ramli, A.; Abu Bakar, M.N.; Osman, N.; Ismail, W.; Sepeai, S. Characterization of novel nitrogen-less derived 2D hybrid perovskite of $\mathrm{C}_{6} \mathrm{H}_{8} \mathrm{~N}_{2} \mathrm{PbBr}_{3}$ as a light-harvesting material for perovskite solar cell application. Mater. Lett. 2018, 227, 62-65. [CrossRef]

44. Sun, Z.Y.; Ma, T.; Tao, H.C.; Fan, Q.; Han, B.X. Fundamentals and challenges of electrochemical $\mathrm{CO}_{2}$ reduction using two-dimensional materials. Chem 2017, 3, 560-587. [CrossRef]

45. Jagadale, A.D.; Guan, G.Q.; Li, X.M.; Du, X.; Ma, X.L.; Hao, X.G.; Abudula, A. Ultrathin nanoflakes of cobalt-manganese layered double hydroxide with high reversibility for asymmetric supercapacitor. J. Power Sour. 2016, 306, 526-534. [CrossRef]

46. Ahmed, N.; Morikawa, M.; Izumi, Y. Photocatalytic conversion of carbon dioxide into methanol using optimized layered double hydroxide catalysts. Catal. Today 2012, 185, 263-269. [CrossRef]

47. Sumboja, A.; Chen, J.W.; Zong, Y.; Lee, P.S.; Liu, Z.L. NiMn layered double hydroxides as efficient electrocatalysts for the oxygen evolution reaction and their application in rechargeable $\mathrm{Zn}$-air batteries. Nanoscale 2017, 9, 774-780. [CrossRef]

48. Zheng, W.R.; Tsang, C.S.; Lee, L.Y.S.; Wong, K.Y. Two-dimensional metal-organic framework and covalent-organic framework: Synthesis and their energy-related applications. Mater. Today Chem. 2019, 12, 34-60. [CrossRef]

49. Bai, W.S.; Li, S.J.; Ma, J.P.; Cao, W.; Zheng, J.B. Ultrathin 2D metal—organic framework (nanosheets and nanofilms)—based xD-2D hybrid nanostructures as biomimetic enzymes and supercapacitors. J. Mater. Chem. A 2019, 7, 9086-9098. [CrossRef]

50. Chandra, D.; Das, S.K.; Bhaumik, A. A fluorophore grafted 2D-hexagonal mesoporous organosilica: Excellent ion-exchanger for the removal of heavy metal ions from wastewater. Microporous Mesoporous Mater. 2010, 128, 34-40. [CrossRef]

51. Mashtalir, O.; Cook, K.M.; Mochalin, V.N.; Crowe, M.; Barsoum, M.W.; Gogotsi, Y. Dye adsorption and decomposition on two-dimensional titanium carbide in aqueous media. J. Mater. Chem. A 2014, 2, 14334-14338. [CrossRef]

52. Cho, S.Y.; Kim, S.J.; Lee, Y.; Kim, J.S.; Jung, W.B.; Yoo, H.W.; Kim, J.; Jung, H.T. Highly enhanced gas adsorption properties in vertically aligned $\mathrm{MoS}_{2}$ layers. ACS Nano 2015, 9, 9314-9321. [CrossRef] [PubMed]

53. Barnabas, M.J.; Parambadath, S.; Mathew, A.; Park, S.S.; Vinu, A.; Ha, C.S. Highly efficient and selective adsorption of $\mathrm{Ln}^{3+}$ on pristine $\mathrm{Zn} / \mathrm{Al}$ layered double hydroxide (Zn/Al-LDH) from aqueous solutions. J. Solid State Chem. 2016, 233, 133-142. [CrossRef]

54. Gu, P.C.; Xing, J.L.; Wen, T.; Zhang, R.; Wang, J.; Zhao, G.X.; Hayat, T.; Ai, Y.J.; Lin, Z.; Wang, X.K. Experimental and theoretical calculation investigation on efficient $\mathrm{Pb}(\mathrm{II})$ adsorption on etched $\mathrm{Ti}_{3} \mathrm{AlC}_{2}$ nanofibers and nanosheets. Environ. Sci. Nano 2018, 5, 946-955. [CrossRef]

55. Li, Y.; Bi, H.Y.; Jin, Y.S. Facile preparation of rhamnolipid-layered double hydroxide nanocomposite for simultaneous adsorption of p-cresol and copper ions from water. Chem. Eng. J. 2017, 308, 78-88. [CrossRef]

56. Yan, L.; Zhou, M.J.; Zhang, X.J.; Huang, L.B.; Chen, W.; Roy, V.A.L.; Zhang, W.J.; Chen, X.F. A novel type of aqueous dispersible ultrathin-layered double hydroxide nanosheets for in vivo bioimaging and drug delivery. ACS Appl. Mater. Interfaces 2017, 9, 34185-34193. [CrossRef]

57. Chen, Y.; Tan, C.; Zhang, H.; Wang, L. Two-dimensional graphene analogues for biomedical applications. Chem. Soc. Rev. 2015, 44, 2681-2701. [CrossRef]

58. Darabdhara, G.; Bordoloi, J.; Manna, P.; Das, M.R. Biocompatible bimetallic Au-Ni doped graphitic carbon nitride sheets: A novel peroxidase-mimicking artificial enzyme for rapid and highly sensitive colorimetric detection of glucose. Sens. Actuator B Chem. 2019, 285, 277-290. [CrossRef]

59. Chen, T.M.; Zou, H.; Wu, X.J.; Liu, C.C.; Situ, B.; Zheng, L.; Yang, G.W. Nanozymatic antioxidant system based on $\mathrm{MoS}_{2}$ nanosheets. ACS Appl. Mater. Interfaces 2018, 10, 12453-12462. [CrossRef]

60. Pavlovic, M.; Rouster, P.; Szilagyi, I. Synthesis and formulation of functional bionanomaterials with superoxide dismutase activity. Nanoscale 2017, 9, 369-379. [CrossRef]

61. Rouster, P.; Pavlovic, M.; Szilagyi, I. Immobilization of Superoxide Dismutase on polyelectrolyte functionalized titania nanosheets. ChemBiochem 2018, 19, 404-410. [CrossRef] [PubMed] 
62. Winterbourn, C.C. Reconciling the chemistry and biology of reactive oxygen species. Nat. Chem. Biol. 2008, 4, 278-286. [CrossRef] [PubMed]

63. Hu, K.S.; Kulkarni, D.D.; Choi, I.; Tsukruk, V.V. Graphene-polymer nanocomposites for structural and functional applications. Prog. Polym. Sci. 2014, 39, 1934-1972. [CrossRef]

64. Wang, J.; Xu, F.; Jin, H.Y.; Chen, Y.Q.; Wang, Y. Non-noble metal-based carbon composites in hydrogen evolution reaction: Fundamentals to applications. Adv. Mater. 2017, 29, 1605838. [CrossRef] [PubMed]

65. Borenstein, A.; Hanna, O.; Attias, R.; Luski, S.; Brousse, T.; Aurbach, D. Carbon-based composite materials for supercapacitor electrodes: A review. J. Mater. Chem. A 2017, 5, 12653-12672. [CrossRef]

66. Jiang, L.B.; Yuan, X.Z.; Pan, Y.; Liang, J.; Zeng, G.M.; Wu, Z.B.; Wang, H. Doping of graphitic carbon nitride for photocatalysis: A reveiw. Appl. Catal. B Environ. 2017, 217, 388-406. [CrossRef]

67. Li, X.M.; Tao, L.; Chen, Z.F.; Fang, H.; Li, X.S.; Wang, X.R.; Xu, J.B.; Zhu, H.W. Graphene and related two-dimensional materials: Structure-property relationships for electronics and optoelectronics. Appl. Phys. Rev. 2017, 4, 021306. [CrossRef]

68. Machado, B.F.; Serp, P. Graphene-based materials for catalysis. Catal. Sci. Technol. 2012, 2, 54-75. [CrossRef]

69. Kong, X.K.; Chen, C.L.; Chen, Q.W. Doped graphene for metal-free catalysis. Chem. Soc. Rev. 2014, 43, 2841-2857. [CrossRef]

70. Dreyer, D.R.; Todd, A.D.; Bielawski, C.W. Harnessing the chemistry of graphene oxide. Chem. Soc. Rev. 2014, 43, 5288-5301. [CrossRef]

71. Gadipelli, S.; Guo, Z.X. Graphene-based materials: Synthesis and gas sorption, storage and separation. Prog. Mater. Sci. 2015, 69, 1-60. [CrossRef]

72. Yang, K.; Feng, L.Z.; Shi, X.Z.; Liu, Z. Nano-graphene in biomedicine: Theranostic applications. Chem. Soc. Rev. 2013, 42, 530-547. [CrossRef] [PubMed]

73. Georgakilas, V.; Tiwari, J.N.; Kemp, K.C.; Perman, J.A.; Bourlinos, A.B.; Kim, K.S.; Zboril, R. Noncovalent functionalization of graphene and graphene oxide for energy materials, biosensing, catalytic, and biomedical applications. Chem. Rev. 2016, 116, 5464-5519. [CrossRef] [PubMed]

74. Li, X.; Yu, J.G.; Wageh, S.; Al-Ghamdi, A.A.; Xie, J. Graphene in Photocatalysis: A Review. Small 2016, 12, 6640-6696. [CrossRef] [PubMed]

75. Liu, J.Q.; Cui, L.; Losic, D. Graphene and graphene oxide as new nanocarriers for drug delivery applications. Acta Biomater. 2013, 9, 9243-9257. [CrossRef] [PubMed]

76. Zou, X.F.; Zhang, L.; Wang, Z.J.; Luo, Y. Mechanisms of the antimicrobial activities of graphene materials. J. Am. Chem. Soc. 2016, 138, 2064-2077. [CrossRef] [PubMed]

77. Yang, K.; Feng, L.Z.; Liu, Z. Stimuli responsive drug delivery systems based on nano-graphene for cancer therapy. Adv. Drug Deliv. Rev. 2016, 105, 228-241. [CrossRef]

78. Vesel, A.; Zaplotnik, R.; Primc, G.; Mozetic, M. Synthesis of vertically oriented graphene sheets or carbon nanowalls-review and challenges. Materials 2019, 12, 2968. [CrossRef]

79. Sun, Y.Q.; Wu, Q.O.; Shi, G.Q. Graphene based new energy materials. Energy Environ. Sci. 2011, 4, 1113-1132. [CrossRef]

80. El-Missiry, M.A. Antioxidant Enzyme; InTech: Rijeka, Croatia, 2012.

81. Brieger, K.; Schiavone, S.; Miller, F.J.; Krause, K.H. Reactive oxygen species: From health to disease. Swiss Med. Wkly. 2012, 142, 13659. [CrossRef]

82. Nirmala, C.; Bisht, M.S.; Bajwa, H.K.; Santosh, O. Bamboo: A rich source of natural antioxidants and its applications in the food and pharmaceutical industry. Trends Food Sci. Technol. 2018, 77, 91-99. [CrossRef]

83. Finley, J.W.; Kong, A.N.; Hintze, K.J.; Jeffery, E.H.; Ji, L.L.; Lei, X.G. Antioxidants in foods: State of the science important to the food industry. J. Agric. Food Chem. 2011, 59, 6837-6846. [CrossRef]

84. Beaucham, C.; Fridovich, I. Superoxide dismutase-improved assays and an assay applicable to acrylamide gels. Anal. Biochem. 1971, 44, 276-287. [CrossRef]

85. Fita, I.; Rossmann, M.G. The active-center of catalase. J. Mol. Biol. 1985, 185, 21-37. [CrossRef]

86. Gajhede, M.; Schuller, D.J.; Henriksen, A.; Smith, A.T.; Poulos, T.L. Crystal structure of horseradish peroxidase C at 2.15 angstrom resolution. Nat. Struct. Biol. 1997, 4, 1032-1038. [CrossRef] [PubMed]

87. Rice-Evans, C.A.; Miller, N.J.; Paganga, G. Structure-antioxidant activity relationships of flavonoids and phenolic acids. Free Radic. Biol. Med. 1996, 20, 933-956. [CrossRef]

88. Brand-Williams, W.; Cuvelier, M.E.; Berset, C. Use of a free-radical method to evaluate antioxidant activity. Food Sci. Technol. Lebensm. Wiss. Technol. 1995, 28, 25-30. [CrossRef] 
89. Fox, J.B. Kinetics and mechanisms of the Griess reaction. Anal. Chem. 1979, 51, 1493-1502. [CrossRef]

90. Re, R.; Pellegrini, N.; Proteggente, A.; Pannala, A.; Yang, M.; Rice-Evans, C. Antioxidant activity applying an improved ABTS radical cation decolorization assay. Free Radic. Biol. Med. 1999, 26, 1231-1237. [CrossRef]

91. Beckman, J.S.; Beckman, T.W.; Chen, J.; Marshall, P.A.; Freeman, B.A. Apparent hydroxyl radical production by peroxynitrite-Implications for endothelial injury from nitric-oxide and superoxide. Proc. Natl. Acad. Sci. USA 1990, 87, 1620-1624. [CrossRef]

92. Koppenol, W.H. The centennial of the Fenton reaction. Free Radic. Biol. Med. 1993, 15, 645-651. [CrossRef]

93. Ohkawa, H.; Ohishi, N.; Yagi, K. Assay for lipid peroxides in animal-tissues by thiobarbituric acid reaction. Anal. Biochem. 1979, 95, 351-358. [CrossRef]

94. Fenton, H.J.H.; Healy, T.W. Oxidation of tartaric acid in presence of iron. J. Chem. Soc. Trans. 1894, 65, 899-910. [CrossRef]

95. Valko, M.; Rhodes, C.J.; Moncol, J.; Izakovic, M.; Mazur, M. Free radicals, metals and antioxidants in oxidative stress-induced cancer. Chem. Biol. Interact. 2006, 160, 1-40. [CrossRef]

96. Benzie, I.F.F.; Strain, J.J. The ferric reducing ability of plasma (FRAP) as a measure of antioxidant power: The FRAP assay. Anal. Biochem. 1996, 239, 70-76. [CrossRef]

97. Apak, R.; Guclu, K.; Ozyurek, M.; Karademir, S.E. Novel total antioxidant capacity index for dietary polyphenols and vitamins $\mathrm{C}$ and $\mathrm{E}$, using their cupric ion reducing capability in the presence of neocuproine: CUPRAC method. J. Agric. Food Chem. 2004, 52, 7970-7981. [CrossRef]

98. Nimse, S.B.; Pal, D. Free radicals, natural antioxidants, and their reaction mechanisms. RSC Adv. 2015, 5, 27986-28006. [CrossRef]

99. Valgimigli, L.; Baschieri, A.; Amorati, R. Antioxidant activity of nanomaterials. J. Mat. Chem. B 2018, 6, 2036-2051. [CrossRef]

100. Mu, J.S.; Wang, Y.; Zhao, M.; Zhang, L. Intrinsic peroxidase-like activity and catalase-like activity of $\mathrm{Co}_{3} \mathrm{O}_{4}$ nanoparticles. Chem. Commun. 2012, 48, 2540-2542. [CrossRef]

101. Dong, J.L.; Song, L.N.; Yin, J.J.; He, W.W.; Wu, Y.H.; Gu, N.; Zhang, Y. $\mathrm{Co}_{3} \mathrm{O}_{4}$ nanoparticles with multi-enzyme activities and their application in immunohistochemical assay. ACS Appl. Mater. Interfaces 2014, 6, 1959-1970. [CrossRef]

102. Wang, Q.; Liu, S.W.; Sun, H.Y.; Lu, Q.F. Synthesis and intrinsic peroxidase-like activity of sisal-like cobalt oxide architectures. Ind. Eng. Chem. Res. 2014, 53, 7917-7922. [CrossRef]

103. Mu, J.S.; Zhang, L.; Zhao, G.Y.; Wang, Y. The crystal plane effect on the peroxidase-like catalytic properties of $\mathrm{Co}_{3} \mathrm{O}_{4}$ nanomaterials. Phys. Chem. Chem. Phys. 2014, 16, 15709-15716. [CrossRef] [PubMed]

104. Zhang, W.; Dong, J.L.; Wu, Y.; Cao, P.; Song, L.N.; Ma, M.; Gu, N.; Zhang, Y. Shape-dependent enzyme-like activity of $\mathrm{Co}_{3} \mathrm{O}_{4}$ nanoparticles and their conjugation with his-tagged EGFR single-domain antibody. Colloid Surf. B Biointerfaces 2017, 154, 55-62. [CrossRef] [PubMed]

105. Sun, H.Y.; Zhu, W.Y. $\mathrm{Co}_{3} \mathrm{O}_{4}$ mirobelts: Preparation with the electrospinning technique and its investigation in peroxidase-like activity. Appl. Surf. Sci. 2017, 399, 298-304. [CrossRef]

106. Alizadeh, N.; Salimi, A.; Hallaj, R. Mimicking peroxidase-like activity of $\mathrm{Co}_{3} \mathrm{O}_{4}-\mathrm{CeO}_{2}$ nanosheets integrated paper-based analytical devices for detection of glucose with smartphone. Sens. Actuator B-Chem. 2019, 288, 44-52. [CrossRef]

107. Wang, Q.Q.; Chen, J.X.; Zhang, H.; Wu, W.W.; Zhang, Z.Q.; Dong, S.J. Porous $\mathrm{Co}_{3} \mathrm{O}_{4}$ nanoplates with pH-switchable peroxidase- and catalase-like activity. Nanoscale 2018, 10, 19140-19146. [CrossRef]

108. Ghosh, S.; Roy, P.; Karmodak, N.; Jemmis, E.D.; Mugesh, G. Nanoisozymes: Crystal-facet-dependent enzyme-mimetic activity of $\mathrm{V}_{2} \mathrm{O}_{5}$ nanomaterials. Angew. Chem. Int. Edit. 2018, 57, 4510-4515. [CrossRef]

109. Tian, R.; Sun, J.H.; Qi, Y.F.; Zhang, B.Y.; Guo, S.L.; Zhao, M.M. Influence of $\mathrm{VO}_{2}$ nanoparticle morphology on the colorimetric assay of $\mathrm{H}_{2} \mathrm{O}_{2}$ and glucose. Nanomaterials 2017, 7, 347. [CrossRef]

110. Kamada, K.; Yamada, A.; Soh, N. Enhanced catalytic activity of enzymes interacting with nanometric titanate nanosheets. RSC Adv. 2015, 5, 85511-85516. [CrossRef]

111. Soh, N.; Kaneko, S.; Uozumi, K.; Ueda, T.; Kamada, K. Preparation of an enzyme/inorganic nanosheet/magnetic bead complex and its enzymatic activity. J. Mater. Sci. 2014, 49, 8010-8015. [CrossRef]

112. Nirala, N.R.; Pandey, S.; Bansal, A.; Singh, V.K.; Mukherjee, B.; Saxena, P.S.; Srivastava, A. Different shades of cholesterol: Gold nanoparticles supported on $\mathrm{MOS}_{2}$ nanoribbons for enhanced colorimetric sensing of free cholesterol. Biosens. Bioelectron. 2015, 74, 207-213. [CrossRef] [PubMed] 
113. Ding, Y.Q.; Wang, G.; Sun, F.Z.; Lin, Y.Q. Heterogeneous nanostructure design based on the epitaxial growth of spongy $\mathrm{MoS}_{\mathrm{x}}$ on $2 \mathrm{D} \mathrm{Co}(\mathrm{OH})(2)$ nanoflakes for triple-enzyme mimetic activity: Experimental and density functional theory studies on the dramatic activation mechanism. ACS Appl. Mater. Interfaces 2018, 10, 32567-32578. [CrossRef]

114. Wu, X.J.; Chen, T.M.; Wang, J.X.; Yang, G.W. Few-layered MoSe $\mathrm{M}_{2}$ nanosheets as an efficient peroxidase nanozyme for highly sensitive colorimetric detection of $\mathrm{H}_{2} \mathrm{O}_{2}$ and xanthine. J. Mater. Chem. B 2018, 6, 105-111. [CrossRef]

115. Huang, L.J.; Zhu, W.X.; Zhang, W.T.; Chen, K.; Wang, J.; Wang, R.; Yang, Q.F.; Hu, N.; Suo, Y.R.; Wang, J.L. Layered vanadium(IV) disulfide nanosheets as a peroxidase-like nanozyme for colorimetric detection of glucose. Microchim. Acta 2018, 185, 7. [CrossRef] [PubMed]

116. Zhang, Y.; Wang, Y.N.; Sun, X.T.; Chen, L.; Xu, Z.R. Boron nitride nanosheet/CuS nanocomposites as mimetic peroxidase for sensitive colorimetric detection of cholesterol. Sens. Actuator B Chem. 2017, 246, 118-126. [CrossRef]

117. Chen, J.Y.; Shu, Y.; Li, H.L.; Xu, Q.; Hu, X.Y. Nickel metal-organic framework 2D nanosheets with enhanced peroxidase nanozyme activity for colorimetric detection of $\mathrm{H}_{2} \mathrm{O}_{2}$. Talanta 2018, 189, 254-261. [CrossRef]

118. Pavlovic, M.; Rouster, P.; Somosi, Z.; Szilagyi, I. Horseradish peroxidase-nanoclay hybrid particles of high functional and colloidal stability. J. Colloid Interface Sci. 2018, 524, 114-121. [CrossRef]

119. Kong, X.G.; Jin, L.; Wei, M.; Duan, X. Antioxidant drugs intercalated into layered double hydroxide: Structure and in vitro release. Appl. Clay Sci. 2010, 49, 324-329. [CrossRef]

120. Ansy, K.M.; Lee, J.H.; Piao, H.; Choi, G.; Choy, J.H. Stabilization of antioxidant gallate in layered double hydroxide by exfoliation and reassembling reaction. Solid State Sci. 2018, 80, 65-71. [CrossRef]

121. Murath, S.; Szerlauth, S.; Sebok, D.; Szilagyi, I. Layered double hydroxide nanoparticles to overcome the hydrophobicity of ellagic acid: An antioxidant hybrid material. Antioxidants 2020, 9, 153. [CrossRef]

122. Amaro, L.P.; Cicogna, F.; Passaglia, E.; Morici, E.; Oberhauser, W.; Al-Malaika, S.; Dintcheva, N.T.; Coiai, S. Thermo-oxidative stabilization of poly(lactic acid) with antioxidant intercalated layered double hydroxides. Polym. Degrad. Stabil. 2016, 133, 92-100. [CrossRef]

123. Pontes-Neto, J.G.; Fontes, D.A.F.; de Lyra, M.A.M.; de Brito, M.D.M.; Chaves, L.L.; Rolim-Neto, P.J.; Soares, M.F.D.; Quintans, L.J.; de Freitas, R.M.; Soares-Sobrinho, J.L. Evaluation of antioxidant potencial of novel CaAl and NiAl layered double hydroxides loaded with olanzapine. Life Sci. 2018, 207, $246-252$. [CrossRef] [PubMed]

124. Pavlovic, M.; Nafradi, M.; Rouster, P.; Murath, S.; Szilagyi, I. Highly stable enzyme-mimicking nanocomposite of antioxidant activity. J. Colloid Interface Sci. 2019, 543, 174-182. [CrossRef] [PubMed]

125. Chen, L.J.; Sun, K.F.; Li, P.P.; Fan, X.Z.; Sun, J.C.; Ai, S.Y. DNA-enhanced peroxidase-like activity of layered double hydroxide nanosheets and applications in $\mathrm{H}_{2} \mathrm{O}_{2}$ and glucose sensing. Nanoscale 2013, 5, 10982-10988. [CrossRef]

126. Olivera, S.; Hu, C.; Nagananda, G.S.; Reddy, N.; Venkatesh, K.; Muralidhara, H.B. Multipurpose composite for heavy metal sorption, antimicrobial, and antioxidant applications. Int. J. Environ. Sci. Technol. 2019, 16, 2017-2030. [CrossRef]

127. Chen, L.J.; Sun, B.; Wang, X.D.; Qiao, F.M.; Ai, S.Y. 2D ultrathin nanosheets of Co-Al layered double hydroxides prepared in L-asparagine solution: Enhanced peroxidase-like activity and colorimetric detection of glucose. J. Mater. Chem. B 2013, 1, 2268-2274. [CrossRef]

128. Zhan, T.R.; Kang, J.X.; Li, X.J.; Pan, L.; Li, G.J.; Hou, W.G. NiFe layered double hydroxide nanosheets as an efficiently mimic enzyme for colorimetric determination of glucose and $\mathrm{H}_{2} \mathrm{O}_{2}$. Sens. Actuator B Chem. 2018, 255, 2635-2642. [CrossRef]

129. Cao, Z.B.; Zhang, L.; Liang, K.; Cheong, S.S.; Boyer, C.; Gooding, J.J.; Chen, Y.; Gu, Z. Biodegradable 2D Fe-Al hydroxide for nanocatalytic tumor-dynamic therapy with tumor specificity. Adv. Sci. 2018, 5, 1801155. [CrossRef]

130. Baek, M.; Choy, J.H.; Choi, S.J. Montmorillonite intercalated with glutathione for antioxidant delivery: Synthesis, characterization, and bioavailability evaluation. Int. J. Pharm. 2012, 425, 29-34. [CrossRef]

131. Gutierrez, T.J.; Ponce, A.G.; Alvarez, V.A. Nano-clays from natural and modified montmorillonite with and without added blueberry extract for active and intelligent food nanopackaging materials. Mater. Chem. Phys. 2017, 194, 283-292. [CrossRef] 
132. Garrido-Miranda, K.A.; Rivas, B.L.; Perez-Rivera, M.A.; Sanfuentes, E.A.; Pena-Farfal, C. Antioxidant and antifungal effects of eugenol incorporated in bionanocomposites of poly(3-hydroxybutyrate)-thermoplastic starch. LWT Food Sci. Technol. 2018, 98, 260-267. [CrossRef]

133. Zhang, L.H.; Gu, C.; Xiong, J.; Yang, M.; Guo, Y. Hemin-histamine-montmorillonite clay conjugate as a model biocatalyst to mimic natural peroxidase. Sci. China Chem. 2015, 58, 731-737. [CrossRef]

134. Yan, W.J.; Chen, W.B.; Muhammad, U.; Zhang, J.H.; Zhuang, H.; Zhou, G.H. Preparation of alpha-tocopherol-chitosan nanoparticles/chitosan/montmorillonite film and the antioxidant efficiency on sliced dry-cured ham. Food Control 2019, 104, 132-138. [CrossRef]

135. Ding, Y.Y.; Sun, L.F.; Jiang, Y.L.; Liu, S.X.; Chen, M.X.; Chen, M.M.; Ding, Y.N.; Liu, Q.Y. A facile strategy for the preparation of $\mathrm{ZnS}$ nanoparticles deposited on montmorillonite and their higher catalytic activity for rapidly colorimetric detection of $\mathrm{H}_{2} \mathrm{O}_{2}$. Mater. Sci. Eng. C Mater. Biol. Appl. 2016, 67, 188-194. [CrossRef]

136. Zhang, L.Y.; Chen, M.X.; Jiang, Y.L.; Chen, M.M.; Ding, Y.A.; Liu, Q.Y. A facile preparation of montmorillonite-supported copper sulfide nanocomposites and their application in the detection of $\mathrm{H}_{2} \mathrm{O}_{2}$. Sens. Actuator B Chem. 2017, 239, 28-35. [CrossRef]

137. Liu, Q.Y.; Jiang, Y.L.; Zhang, L.Y.; Zhou, X.P.; Lv, X.T.; Ding, Y.Y.; Sun, L.F.; Chen, P.P.; Yin, H.L. The catalytic activity of $\mathrm{Ag}_{2} \mathrm{~S}$-montmorillonites as peroxidase mimetic toward colorimetric detection of $\mathrm{H}_{2} \mathrm{O}_{2}$. Mater. Sci. Eng. C Mater. Biol. Appl. 2016, 65, 109-115. [CrossRef]

138. Wu, K.L.; Yang, B.C.; Zhu, X.X.; Chen, W.; Luo, X.L.; Liu, Z.X.; Zhang, X.; Liu, Q.Y. Cobalt and nickel bimetallic sulfide nanoparticles immobilized on montmorillonite demonstrating peroxidase-like activity for $\mathrm{H}_{2} \mathrm{O}_{2}$ detection. New J. Chem. 2018, 42, 18749-18758. [CrossRef]

139. Kim, H.J.; Suma, Y.; Lee, S.H.; Kim, J.A.; Kim, H.S. Immobilization of horseradish peroxidase onto clay minerals using soil organic matter for phenol removal. J. Mol. Catal. B Enzym. 2012, 83, 8-15. [CrossRef]

140. Szilagyi, I.; Labadi, I.; Hernadi, K.; Palinko, I.; Fekete, I.; Korecz, L.; Rockenbauer, A.; Kiss, T. Superoxide dismutase activity of a Cu-Zn complex-bare and immobilised. New J. Chem. 2005, 29, 740-745. [CrossRef]

141. Szilagyi, I.; Labadi, I.; Hernadi, K.; Kiss, T.; Palinko, I. Montmorillonite intercalated Cu(II)-histidine complex - synthesis, characterisation and superoxide dismutase activity. In Molecular Sieves: From Basic Research to Industrial Applications, Pts a and B; Cejka, J., Zilkova, N., Nachtigall, P., Eds.; Elsevier: Amsterdam, The Netherland, 2005; Volume 158, pp. 1011-1018.

142. He, Y.F.; Qi, F.; Niu, X.H.; Zhang, W.C.; Zhang, X.F.; Pan, J.M. Uricase-free on-demand colorimetric biosensing of uric acid enabled by integrated $\mathrm{CoP}$ nanosheet arrays as a monolithic peroxidase mimic. Anal. Chim. Acta 2018, 1021, 113-120. [CrossRef]

143. Alizadeh, N.; Salimi, A.; Hallaj, R. Mimicking peroxidase activity of $\mathrm{Co}-2(\mathrm{OH})(2) \mathrm{CO}_{3}-\mathrm{CeO}_{2}$ nanocomposite for smartphone based detection of tumor marker using paper-based microfluidic immunodevice. Talanta 2018, 189, 100-110. [CrossRef] [PubMed]

144. Guo, J.L.; Wang, Y.; Zhao, M. 3D flower-like ferrous(II) phosphate nanostructures as peroxidase mimetics for sensitive colorimetric detection of hydrogen peroxide and glucose at nanomolar level. Talanta 2018, 182, 230-240. [CrossRef] [PubMed]

145. Tanaka, S.; Masud, M.K.; Kaneti, Y.V.; Shiddiky, M.J.A.; Fatehmulla, A.; Aldhafiri, A.M.; Farooq, W.A.; Bando, Y.; Hossain, M.S.A.; Yamauchi, Y. Enhanced peroxidase mimetic activity of porous iron oxide nanoflakes. ChemNanoMat 2019, 5, 506-513. [CrossRef]

146. Wang, T.; Su, P.; Lin, F.Y.; Yang, Y. Self-sacrificial template synthesis of mixed-valence-state cobalt nanomaterials with high catalytic activities for colorimetric detection of glutathione. Sens. Actuator $B$ Chem. 2018, 254, 329-336. [CrossRef]

147. Ganganboina, A.B.; Doong, R.A. The biomimic oxidase activity of layered $\mathrm{V}_{2} \mathrm{O}_{5}$ nanozyme for rapid and sensitive nanomolar detection of glutathione. Sens. Actuator B Chem. 2018, 273, 1179-1186. [CrossRef]

148. Xie, Q.; Zhao, Y.Y.; Chen, X.; Liu, H.M.; Evans, D.G.; Yang, W.S. Nanosheet-based titania microspheres with hollow core-shell structure encapsulating horseradish peroxidase for a mediator-free biosensor. Biomaterials 2011, 32, 6588-6594. [CrossRef]

149. Rouster, P.; Pavlovic, M.; Saringer, S.; Szilagyi, I. Functionalized titania nanosheet dispersions of peroxidase activity. J. Phys. Chem. C 2018, 122, 11455-11463. [CrossRef]

150. Niu, Y.Y.; Zou, R.Y.; Yones, H.A.; Li, X.B.; Li, X.Y.; Niu, X.L.; Chen, Y.; Li, P.; Sun, W. Electrochemical behavior of horseradish peroxidase on $\mathrm{WS}_{2}$ nanosheet-modified electrode and electrocatalytic investigation. J. Chin. Chem. Soc. 2018, 65, 1127-1135. [CrossRef] 
151. Huang, Y.; Zhao, M.T.; Han, S.K.; Lai, Z.C.; Yang, J.; Tan, C.L.; Ma, Q.L.; Lu, Q.P.; Chen, J.Z.; Zhang, X.; et al. Growth of Au nanoparticles on 2D metalloporphyrinic metal-organic framework nanosheets used as biomimetic catalysts for cascade reactions. Adv. Mater. 2017, 29, 1700102. [CrossRef]

152. Qin, L.; Wang, X.Y.; Liu, Y.F.; Wei, H. 2D-metal-organic-framework-nanozyme sensor arrays for probing phosphates and their enzymatic hydrolysis. Anal. Chem. 2018, 90, 9983-9989. [CrossRef]

153. Liu, X.P.; Yan, Z.Q.; Zhang, Y.; Liu, Z.W.; Sun, Y.H.; Ren, J.S.; Qu, X.G. Two-dimensional metal-organic framework/enzyme hybrid nanocatalyst as a benign and $\mathrm{m}$ self-activated cascade reagent for in vivo wound healing. ACS Nano 2019, 13, 5222-5230. [CrossRef] [PubMed]

154. Wang, Y.L.; Wang, Z.C.; Rui, Y.P.; Li, M.G. Horseradish peroxidase immobilization on carbon nanodots/CoFe layered double hydroxides: Direct electrochemistry and hydrogen peroxide sensing. Biosens. Bioelectron. 2015, 64, 57-62. [CrossRef] [PubMed]

155. Zhang, Q.; Jiao, Q.; Leroux, F.; Tang, P.G.; Li, D.Q.; Feng, Y.J. Antioxidant intercalated hydrocalumite as multifunction nanofiller for Poly(propylene): Synthesis, thermal stability, light stability, and anti-migration property. Polym. Degrad. Stabil. 2017, 140, 9-16. [CrossRef]

156. Lonkar, S.P.; Kutlu, B.; Leuteritz, A.; Heinrich, G. Nanohybrids of phenolic antioxidant intercalated into MgAl-layered double hydroxide clay. Appl. Clay Sci. 2013, 71, 8-14. [CrossRef]

157. Badhani, B.; Sharma, N.; Kakkar, R. Gallic acid: A versatile antioxidant with promising therapeutic and industrial applications. RSC Adv. 2015, 5, 27540-27557. [CrossRef]

158. Arratia-Quijada, J.; Rivas-Fuentes, S.; Saavedra, K.J.P.; Lamas, A.M.M.; Arizaga, G.G.C. Layered double hydroxide as a vehicle to increase toxicity of gallate ions against Adenocarcinoma cells. Molecules 2016, 21, 928. [CrossRef] [PubMed]

159. Lima, E.; Flores, J.; Cruz, A.S.; Leyva-Gomez, G.; Krotzsch, E. Controlled release of ferulic acid from a hybrid hydrotalcite and its application as an antioxidant for human fibroblasts. Microporous Mesoporous Mater. 2013, 181, 1-7. [CrossRef]

160. Gao, X.R.; Lei, L.X.; O'Hare, D.; Xie, J.; Gao, P.R.; Chang, T. Intercalation and controlled release properties of vitamin C intercalated layered double hydroxide. J. Solid State Chem. 2013, 203, 174-180. [CrossRef]

161. Gao, X.R.; Chen, L.; Xie, J.; Yin, Y.B.; Chang, T.; Duan, Y.C.; Jiang, N. In vitro controlled release of vitamin C from Ca/Al layered double hydroxide drug delivery system. Mater. Sci. Eng. C Mater. Biol. Appl. 2014, 39, 56-60. [CrossRef] [PubMed]

162. Shafiei, S.S.; Solati-Hashjin, M.; Samadikuchaksaraei, A.; Kalantarinejad, R.; Asadi-Eydivand, M.; Abu Osman, N.A. Epigallocatechin gallate/layered double hydroxide nanohybrids: Preparation, characterization, and in vitro anti-tumor study. PLOS ONE 2015, 10, e0136530. [CrossRef]

163. Feng, Y.J.; Jiang, Y.; Huang, Q.; Chen, S.T.; Zhang, F.B.; Tang, P.G.; Li, D.Q. High antioxidative performance of layered double hydroxides/polypropylene composite with intercalation of low-molecular-weight phenolic antioxidant. Ind. Eng. Chem. Res. 2014, 53, 2287-2292. [CrossRef]

164. Zhang, Q.; Jiao, Q.; Leroux, F.; Tang, P.G.; Li, D.Q.; Feng, Y.J. Antioxidant intercalated Zn-containing layered double hydroxides: Preparation, performance and migration properties. New J. Chem. 2017, 41, 2364-2371. [CrossRef]

165. Camino, G.; Maffezzoli, A.; Braglia, M.; De Lazzaro, M.; Zammarano, M. Effect of hydroxides and hydroxycarbonate structure on fire retardant effectiveness and mechanical properties in ethylene-vinyl acetate copolymer. Polym. Degrad. Stabil. 2001, 74, 457-464. [CrossRef]

166. Yu, J.F.; Liu, J.J.; Clearfield, A.; Sims, J.E.; Speiegle, M.T.; Suib, S.L.; Sun, L.Y. Synthesis of layered double hydroxide single-layer nanosheets in formamide. Inorg. Chem. 2016, 55, 12036-12041. [CrossRef] [PubMed]

167. Lonkar, S.P.; Leuteritz, A.; Heinrich, G. Antioxidant intercalated layered double hydroxides: A new multifunctional nanofiller for polymers. RSC Adv. 2013, 3, 1495-1501. [CrossRef]

168. Ranjekar, P.K.; Hinge, A.; Hegde, M.V.; Ghate, M.; Kale, A.; Sitasawad, S.; Wagh, U.V.; Debsikdar, V.B.; Mahadik, S.P. Decreased antioxidant enzymes and membrane essential polyunsaturated fatty acids in schizophrenic and bipolar mood disorder patients. Psychiatry Res. 2003, 121, 109-122. [CrossRef]

169. Fernandez, L.; Ledezma, I.; Borras, C.; Martinez, L.A.; Carrero, H. Horseradish peroxidase modified electrode based on a film of Co-Al layered double hydroxide modified with sodium dodecylbenzenesulfonate for determination of 2-chlorophenol. Sens. Actuator B Chem. 2013, 182, 625-632. [CrossRef] 
170. Zhang, F.T.; Long, X.; Zhang, D.W.; Sun, Y.L.; Zhou, Y.L.; Ma, Y.R.; Qi, L.M.; Zhang, X.X. Layered double hydroxide-hemin nanocomposite as mimetic peroxidase and its application in sensing. Sens. Actuator B-Chem. 2014, 192, 150-156. [CrossRef]

171. Qiao, F.M.; Shi, W.J.; Dong, J.; Lv, W.; Ai, S.Y. Functional hybrids of layered double hydroxides with hemin: Synergistic effect for peroxynitrite-scavenging activity. RSC Adv. 2014, 4, 44614-44620. [CrossRef]

172. Zhang, Y.W.; Tian, J.Q.; Liu, S.; Wang, L.; Qin, X.Y.; Lu, W.B.; Chang, G.H.; Luo, Y.L.; Asiri, A.M.; Al-Youbi, A.O.; et al. Novel application of CoFe layered double hydroxide nanoplates for colorimetric detection of $\mathrm{H}_{2} \mathrm{O}_{2}$ and glucose. Analyst 2012, 137, 1325-1328. [CrossRef]

173. Su, L.; Yu, X.A.; Miao, Y.Q.; Mao, G.J.; Dong, W.P.; Feng, S.L.; Liu, S.M.; Yang, L.K.; Zhang, K.G.; Zhang, H. Alkaline-promoted regulation of the peroxidase-like activity of $\mathrm{Ni} / \mathrm{Co} \mathrm{LDHs}$ and development bioassays. Talanta 2019, 197, 181-188. [CrossRef] [PubMed]

174. Wu, L.H.; Wan, G.P.; Shi, S.H.; He, Z.Y.; Xu, X.F.; Tang, Y.L.; Hao, C.C.; Wang, G.Z. Atomic layer deposition-assisted growth of $\mathrm{CuAl} \mathrm{LDH}$ on carbon fiber as a peroxidase mimic for colorimetric determination of $\mathrm{H}_{2} \mathrm{O}_{2}$ and glucose. New J. Chem. 2019, 43, 5826-5832. [CrossRef]

175. Xu, X.C.; Zou, X.B.; Wu, S.W.; Wang, L.J.; Niu, X.H.; Li, X.; Pan, J.M.; Zhao, H.L.; Lan, M.B. In situ formation of fluorescent polydopamine catalyzed by peroxidase-mimicking FeCo-LDH for pyrophosphate ion and pyrophosphatase activity detection. Anal. Chim. Acta 2019, 1053, 89-97. [CrossRef] [PubMed]

176. Ruan, Y.D.; Jia, X.D.; Wang, C.; Zhen, W.Y.; Jiang, X. Mn-Fe layered double hydroxide nanosheets: A new photothermal nanocarrier for O-2-evolving phototherapy. Chem. Commun. 2018, 54, 11729-11732. [CrossRef] [PubMed]

177. Souza, V.G.L.; Pires, J.R.A.; Vieira, E.T.; Coelhoso, I.M.; Duarte, M.P.; Fernando, A.L. Activity of chitosan-montmorillonite bionanocomposites incorporated with rosemary essential oil: From in vitro assays to application in fresh poultry meat. Food Hydrocoll. 2019, 89, 241-252. [CrossRef]

178. Bhattacharyya, D.K.; Bandyopadhyay, U.; Banerjee, R.K. Chemical and kinetic evidence for an essential histidine in horseradish-peroxidase for iodide oxidation. J. Biol. Chem. 1992, 267, 9800-9804. [PubMed]

179. Zhou, F.F.; Luo, J.Q.; Qi, B.K.; Chen, X.R.; Wan, Y.H. Horseradish peroxidase immobilized on multifunctional hybrid microspheres for aflatoxin B1 removal: Will enzymatic reaction be enhanced by adsorption? Ind. Eng. Chem. Res. 2019, 58, 11710-11719. [CrossRef]

180. Pires, J.R.A.; de Souza, V.G.L.; Fernando, A.L. Chitosan/montmorillonite bionanocomposites incorporated with rosemary and ginger essential oil as packaging for fresh poultry meat. Food Packag. Shelf Life 2018, 17, 142-149. [CrossRef]

181. Souza, V.G.L.; Pires, J.R.A.; Rodrigues, P.F.; Lopes, A.A.S.; Fernandes, F.M.B.; Duarte, M.P.; Coelhoso, I.M.; Fernando, A.L. Bionanocomposites of chitosan/montmorillonite incorporated with Rosmarinus officinalis essential oil: Development and physical characterization. Food Packag. Shelf Life 2018, 16, 148-156. [CrossRef]

182. Szilagyi, I.; Horvath, L.; Labadi, I.; Hernadi, K.; Palinko, I.; Kiss, T. Mimicking catalase and catecholase enzymes by copper(II)-containing complexes. Cent. Eur. J. Chem. 2006, 4, 118-134. [CrossRef]

183. Deshapriya, I.K.; Kim, C.S.; Novak, M.J.; Kumar, C.V. Biofunctionalization of alpha-Zirconium Phosphate Nanosheets: Toward Rational Control of Enzyme Loading, Affinities, Activities and Structure Retention. ACS Appl. Mater. Interfaces 2014, 6, 9643-9653. [CrossRef] [PubMed]

(C) 2020 by the authors. Licensee MDPI, Basel, Switzerland. This article is an open access article distributed under the terms and conditions of the Creative Commons Attribution (CC BY) license (http://creativecommons.org/licenses/by/4.0/). 